\title{
Do Foldable Containers Enhance Efficient Empty Container Repositioning under Demand Fluctuation?-Case of the Pacific Region
}

\author{
Zirui Liang ${ }^{1}{ }^{1}$, Ryuichi Shibasaki ${ }^{2, *} \mathbb{1}$ and Yuji Hoshino ${ }^{3}$ \\ 1 Department of Systems Innovation, School of Engineering, The University of Tokyo, Tokyo 113-8656, Japan; \\ liangzirui@g.ecc.u-tokyo.ac.jp \\ 2 Resilience Engineering Research Center, Department of Technology Management for Innovation, \\ School of Engineering, The University of Tokyo, Tokyo 113-8656, Japan \\ 3 Boxtics Inc., Tokyo 107-0061, Japan; hoshino@boxtics.co.jp \\ * Correspondence: shibasaki@tmi.t.u-tokyo.ac.jp; Tel.: +81-3-5841-6546
}

Citation: Liang, Z.; Shibasaki, R.;

Hoshino, Y. Do Foldable Containers Enhance Efficient Empty Container Repositioning under Demand Fluctuation?-Case of the Pacific Region. Sustainability 2021, 13, 4730. https://doi.org/10.3390/su13094730

Academic Editor: Arijit De

Received: 28 February 2021

Accepted: 19 April 2021

Published: 23 April 2021

Publisher's Note: MDPI stays neutral with regard to jurisdictional claims in published maps and institutional affiliations.

Copyright: (c) 2021 by the authors. Licensee MDPI, Basel, Switzerland. This article is an open access article distributed under the terms and conditions of the Creative Commons Attribution (CC BY) license (https:// creativecommons.org/licenses/by/ $4.0 /)$.

\begin{abstract}
This study considers the empty container repositioning problem of shipping companies that use standard and 3-in-1 foldable containers with more advanced designs. A mathematical model is developed to compare the total management costs of container repositioning of various patterns in different cargo shipping demand scenarios. Numerous scenario analyses and simulations of empty container repositioning were conducted, focusing on a liner shipping service in the Pacific Islands where empty containers are likely to be present because of the imbalance between inbound and outbound flows of containers, including static analysis and consecutive analysis with demand fluctuation in different approaches. Results show that with the introduction of foldable containers, depending on the growth rate of container cargo shipping demand, the total management costs of empty container repositioning can be reduced. However, introducing a large number of foldable containers may increase the total management costs of container repositioning. Moreover, the cost reduction effect of adding another containership increases in cases where future cargo shipping demand increases substantially. Furthermore, the introduction of foldable containers not only effectively reduces the management costs of empty containers, but also makes costs more stable and predictable.
\end{abstract}

Keywords: maritime container shipping; empty container repositioning; foldable containers; Pacific Islands; static analysis; consecutive analysis; demand fluctuation

\section{Introduction}

In recent years, rapid economic growth and globalization have led to a substantial increase in container cargo shipping demand and growing trade imbalances between imports and exports among different regions, resulting in an imbalance between the inbound and outbound flows of full containers. Therefore, repositioning a large number of empty containers from the surplus to deficit areas is necessary. If the repositioned empty containers cannot temporally meet the required number at the ports in the deficit area, the leased containers would be offset by the shortage. However, the remaining empty containers that cannot be repositioned should be stored in the surplus area. The cost burden of remedying the excess or deficiency of empty containers has become a major pressure on container shipping companies, and it may affect the stable supply of container shipping services; therefore, repositioning empty containers has become an important issue in the management of shipping services [1].

One of the difficulties of repositioning empty containers is that they require the same spaces for transport and storage as full containers. To alleviate this problem, introducing foldable containers is a possible solution. Figure 1 shows the folding process of a foldable 
container. Less space is required if an empty container is folded, leading to multiple foldable containers being folded into the equivalent dimensions of a standard container. Therefore, containerships and the storage space can be used more efficiently, resulting in reduced transport costs, storage costs, and handling times of containers. In some cases, empty containers that cannot be repositioned may be sold or discarded in the surplus area, and new ones purchased in the deficit area. If foldable containers are introduced, more containers can be reused, reducing resource wastage. Moreover, this contributes to the reduction of road traffic volume, port congestion, and carbon emissions. Therefore, introducing foldable containers can contribute to increasing sustainability.

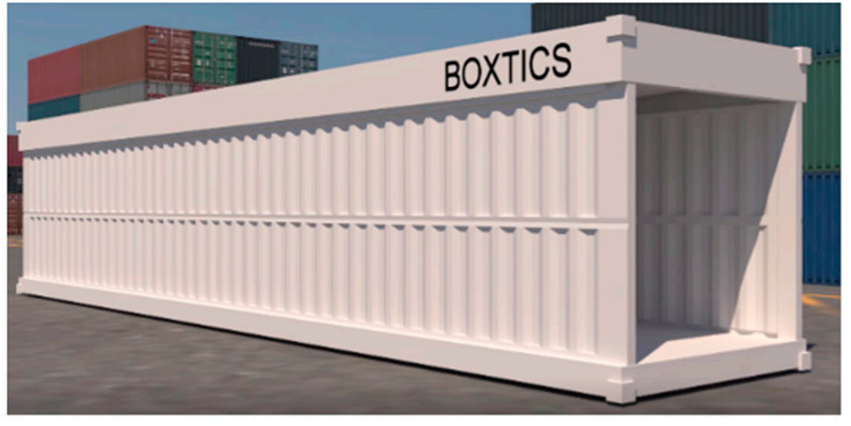

(a)

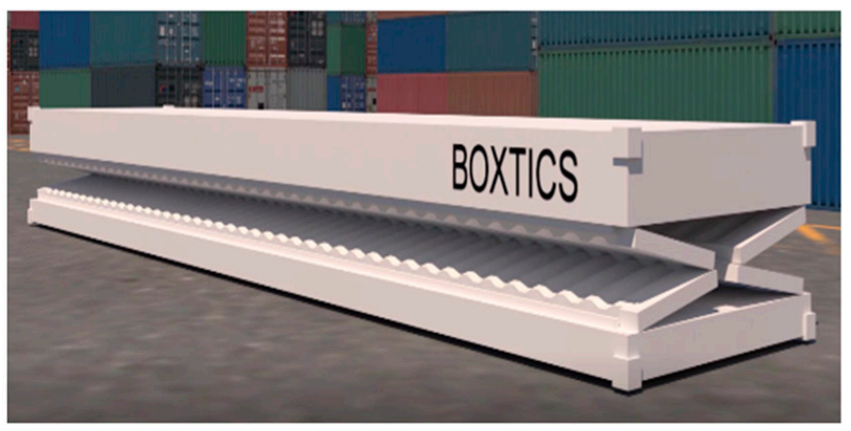

(c)

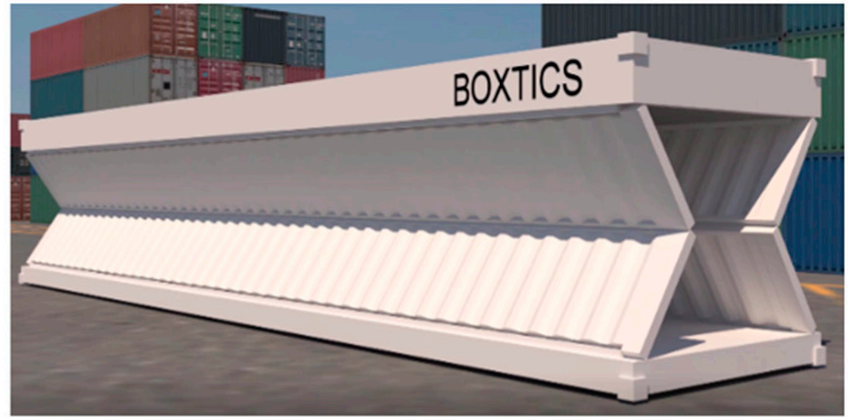

(b)

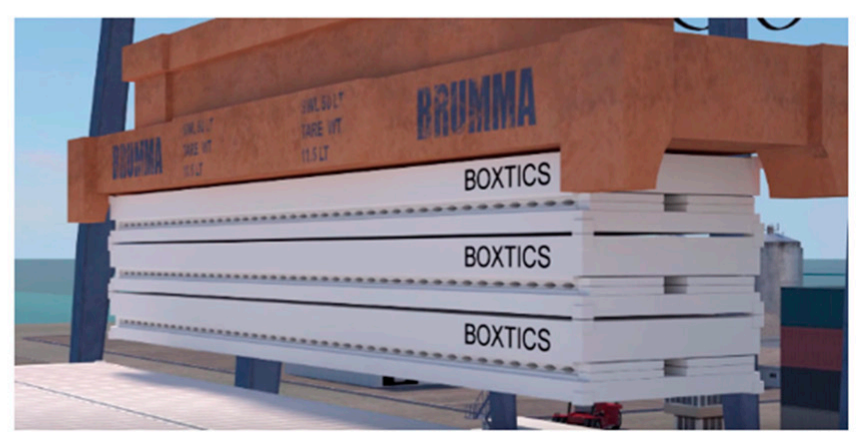

(d)

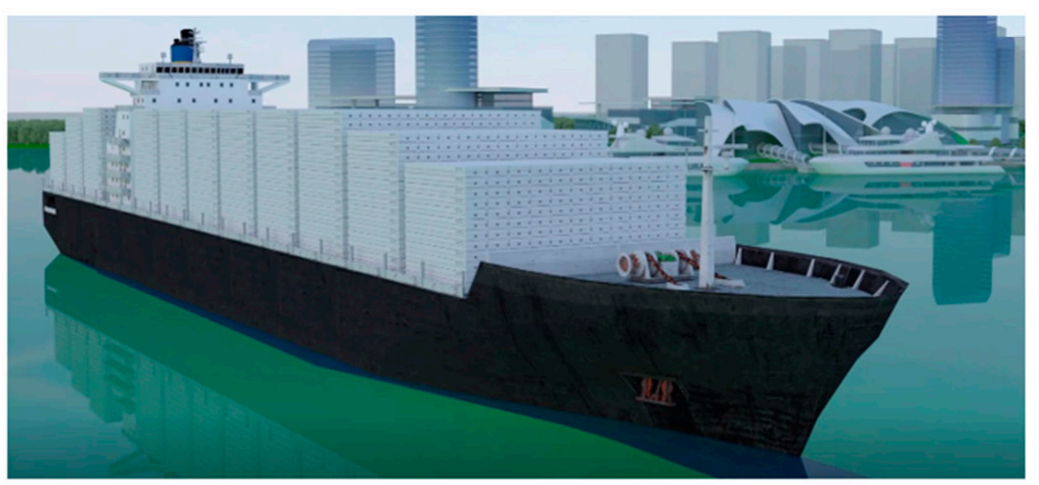

(e)

Figure 1. Folding, bundling, and stacking process of the foldable container. (a) Original state of the container, (b) beginning of folding process, (c) end of folding process, (d) bundling process, (e) stacked on containers ship. Source: Boxtics Inc. [2]. 
However, foldable containers have not yet been put into practical use, although their concept has already been established, because their merits have not yet been fully revealed. Designs of foldable containers, which affect the additional costs, including the costs of the folding and unfolding processes, manufacturing, maintenance, and repair, are key to their use [3]. A Japanese company has designed a 3-in-1 foldable container that can be folded and unfolded with just one button, which can save the cost and time of folding and unfolding, enabling the containers to be more economical and practical [2].

By comparing the management costs of empty container repositioning between cases where only standard containers are used, and where only the 3-in-1 foldable containers are introduced, this study aims to determine the situations wherein foldable containers can be advantageous in empty container repositioning from an economic perspective. To solve this problem, we formulated an empty container repositioning problem concerning the transport of full containers, focused on a liner shipping service in the Pacific island countries (PICs). This implied that the introduction of foldable containers may reduce the total management cost of container repositioning in some situations by static and consecutive analysis, depending on the current fluctuations and future growth rates of cargo shipping demand. The volume of containerized cargo generated at a port varies according to the shipping market conditions and seasons [4]. Therefore, considering such changeable demands and analyzing various possible scenarios are necessary.

We focused on PICs because empty containers are likely to occur here, since the volume of import of full containers is much greater than that of export containers, as shown in Table 1. Because PICs have few domestic industries aside from agriculture and fishery, they rely heavily on imports to meet the demand for basic goods, which are primarily transported through maritime shipping, including food, fuel, medicine, and productive resources such as commercial machinery and appliances. In contrast, exports from PICs are typically lower in value and consist of a limited range of goods, often resulting in heavy imbalances in trade [5]. Therefore, the imports far outweigh the exports in most PICs. In some cases, this imbalance is extreme, such as in Wallis and Futuna, where the full container rate of imports to exports is approximately 30:1. More typically, the rate is in the range of 2:1 to 20:1. Therefore, the effect of introducing foldable containers to remedy the excess or deficiency of empty containers in PICs is expected.

The Pacific region consists of numerous islands dispersed across the southwest Pacific Ocean that are sometimes called "sea-locked countries" [6]. The region has suffered from high costs of participating in international trade, due to its remoteness from the world's major markets. The dispersed nature of the region also leads to expensive transport costs, especially when connecting smaller remote islands. Empty containers are not only an issue in terms of transport efficiency, but also seriously undermine the profitability of the liner shipping companies (LSCs) operating in PICs. LSCs often receive subsidies from Pacific island governments to maintain their operations in the region.

The remainder of this paper is organized as follows. Section 2 reviews the relevant literature. Specific factors for repositioning empty containers when considering foldable containers are analyzed in Section 3. Section 4 presents a description and formulation of the problem that needs to be solved. Section 5 introduces some static analyses, considering both cargo shipping demand with smaller increasing rates and higher ones. Consecutive analyses with two different approaches to demand fluctuation are also analyzed in Section 6. Finally, Section 7 concludes this study and discusses future research directions. 
Table 1. Annual volumes of export and import full containers at PIC ports (as of 2018). Source: compiled by the authors, based on GTA forecasting.

\begin{tabular}{cccc}
\hline Port & \multicolumn{3}{c}{ Export and Import Full Containers (TEU/year) } \\
\hline & Total & Export & Import \\
\hline Apra (Guam) & 4391 & 704 & 3687 \\
Saipan Island (Northern Mariana Islands) & 2422 & 137 & 2285 \\
Koror (Palau) & 3928 & 281 & 3647 \\
Pohnpei (Micronesia) & 11,491 & 7243 & 4248 \\
Majuro (Marshall Islands) & 26,246 & 10,962 & 15,284 \\
Betio (Kiribati) & 11,116 & 7650 & 3466 \\
Port Funafuti (Tuvalu) & 7873 & 1404 & 6469 \\
Nauru (Nauru) & 5603 & 517 & 5086 \\
Futuna (Wallis \& Futuna) & 1217 & 40 & 1177 \\
Lae (PNG) & 111,666 & 39,382 & 72,284 \\
Madang (PNG) & 8486 & 3337 & 5149 \\
Port Moresby (PNG) & 48,162 & 8566 & 39,596 \\
Rabaul (PNG) & 13,520 & 4783 & 8737 \\
Honiara (Solomon Islands) & 60,411 & 50,916 & 9495 \\
Noro (Solomon Islands) & 10,069 & 8486 & 1583 \\
Port Vila (Vanuatu) & 11,239 & 3802 & 7437 \\
Santo (Vanuatu) & 4879 & 1167 & 3712 \\
Lautoka (Fiji) & 41,358 & 21,592 & 19,766 \\
Suva (Fiji) & 13,4178 & 43,183 & 90,995 \\
Noumea (New Caledonia) & 57,594 & 22,759 & 34,835 \\
Apia (Samoa) & 14,786 & 2059 & 12,727 \\
Pago Pago (American Samoa) & 5681 & 1196 & 4485 \\
Nukualofa (Tonga) & 7851 & 927 & 6924 \\
Alofi (Niue) & 1033 & 145 & 888 \\
Rarotonga (Cook Islands) & 4355 & 553 & 3802 \\
Papeete (French Polynesia) & 30,220 & 1436 & 28,784 \\
PIC Ports Total & 645,071 & 248,523 & 396,548 \\
\hline
\end{tabular}

\section{Literature Review}

Several studies have explored the potential benefits of foldable containers in container repositioning. Konings [7] analyzed the economic and logistical viability of introducing foldable containers through a cost-benefit analysis, showing that the use of foldable containers could lead to substantial net benefits in the total chain of container transport. However, he also pointed out the additional costs of introducing foldable containers. Shintani et al. [3] modeled the entire empty container flow as an integer programming problem with different strategies in an empty container flow itinerary, and discovered the possibility of saving container fleet management costs by repositioning empty containers through the use of foldable containers. Shintani et al. [8] also proposed an integer programming model to determine which among the three container fleet configurations (i.e., foldable containers only, standard containers only, or a mix of foldable containers and standard containers) would minimize the shipping company's container management costs, and they revealed that a mix of foldable containers and standard containers would provide the best solution. Moon et al. [9] compared the repositioning costs of foldable containers to those of standard containers, using mathematical models with heuristic algorithms to minimize the total relevant cost, including the folding/unfolding, inventory storage, container purchasing, and repositioning costs. Sensitivity analysis revealed that a decrease in the production cost of foldable containers and an increase in transportation costs play a key role in the use of foldable containers. Myung and Moon [10] addressed a multi-port and multi-period container planning problem for shipping companies considering both standard and foldable containers, using a network flow model which optimally allocated both foldable and standard containers to minimize the total purchasing, repositioning, and storage costs. They also pointed out the necessity of determining the rate of foldable 
containers within a defined period. Bandara et al. [11] demonstrated, through a simulation for the port of Melbourne, that using foldable containers would reduce the total number of containers handled in the port, and then generate numerous benefits, such as reductions in capacity constraints at loading and storage centers, and a reduction in port infrastructure expansion costs. Therefore, foldable containers can contribute to the sustainability of the shipping industry. Moon and Hong [12] developed a mathematical model for repositioning both standard and foldable empty containers, which minimizes the total costs for transportation, inventory holding, handling, folding/unfolding, container leasing, and installing facilities that accommodate foldable containers. Linear programming-based and hybrid genetic algorithms have been used to obtain satisfactory solutions for these problems. Wang et al. [13] addressed the problem of ship-type decisions concerning empty container repositioning and foldable containers, which determines the capacity of ships deployed in a trans-Pacific shipping service route at a tactical level, and empty container repositioning between ports at an operational level. Optimal decisions of ship type can help the effective use of the vessel capacity, and thus promote the sustainability of the shipping industry. Zhang et al. [14] developed a mixed-integer linear programming model to determine the optimal empty container repositioning with foldable containers on the intermodal transportation network related to China's Belt and Road Initiative. Goh [15] investigated foldable containers from the shipper and sustainability perspectives. In particular, the viability of foldable containers as an instrument of carbon offsetting for the shipping industry was explored. Zhang et al. [16] investigated the potential of foldable containers to improve empty container repositioning in river-sea intermodal transport along the Yangtze River in China, taking into consideration bridge height and water depth constraints. Their results showed that introducing foldable containers into empty container repositioning along a river could encourage companies to use vessel space more effectively and decrease the total cost for shipping companies, ensuring their sustainability. Moreover, earlier research $[11,15,17,18]$ demonstrated that foldable containers could help in reducing the carbon footprint of the shipping industry because the number of shipments could be reduced by folding and bundling the empty containers, which is an increasingly important global sustainability issue.

These studies considered certain factors related to foldable containers in empty container repositioning and revealed the economic and environmental benefits of foldable containers. However, none of them considered conducting consecutive analyses to compare the management costs of empty container repositioning when using only standard containers and introducing foldable containers under demand fluctuation. Lee and Moon [19] proposed a robust formulation that requires only limited information about the distribution of demand to replicate real-world situations for the empty container repositioning problem between North America and Asia, considering foldable containers under demand uncertainty. Even in the context of studies on empty container repositioning management without foldable containers being introduced, only a few studies considered the problem under demand fluctuation, as summarized in Kuzmicz and Pesch [20]. Lam et al. [21] demonstrated the application of a dynamic stochastic model for repositioning empty containers. They used the contracting value iteration algorithm to obtain the exact optimal average cost solution. Song and Zhang [22] applied a fluid flow model to determine the optimal empty container repositioning policy in a single-port system, with stochastic demand modeled using a two-state Markov process. They characterized the underlying dynamics and followed the dynamic programming approach to obtain a closed-form solution to the optimal control problem. Song and Dong [23] considered both fleet sizing and empty container repositioning under uncertain demand on a liner shipping system with a transAtlantic service. They considered three types of distributions (i.e., exponential, uniform, and normal distributions) for daily demands. Zhang et al. [24] considered repositioning empty containers between multiple ports over multiple periods with stochastic demand and lost sales. Numerical examples were provided to illustrate the solution procedures, based on normal and uniform distributions. Dong and Song [25] considered the joint 
container fleet sizing and the repositioning problem of empty containers in multi-vessel, multi-port, and multi-voyage shipping systems with dynamic, uncertain, and imbalanced customer demands, and they applied them to a trans-Pacific shipping service and a EuropeAsia shipping service. They also compared the total costs for uniform distributions and normal distributions of customer demands under three policies: non-repositioning, heuristics repositioning, and evolutionary algorithm-based policies. In general, these studies represented the uncertainty of customer demand by probability distributions, including uniform, normal, and exponential distributions, and dynamic programming methodologies were used to obtain optimal cost solutions under different scenarios.

Table 2 summarizes the characteristics of the above studies. As shown in the table, to the best of our knowledge, no studies have considered the impact of introducing foldable containers under demand fluctuation, except for Lee and Moon [19]. However, they did not consider various patterns of demand fluctuation, which are essential to consider in order to reflect the real maritime container shipping market and were considered in certain studies on empty container repositioning without foldable containers being introduced. This study aims to fill this research gap. Moreover, in contrast to Lee and Moon [19], this study considers: (1) the proportion of foldable containers introduced to the container repositioning system, which would significantly affect the total management costs of empty container repositioning; and (2) the cost reduction effect of adding another containership to reposition empty containers, considering the significant increase in future cargo shipping demand. Furthermore, this study focuses on the Pacific region as an application of the empty container repositioning problem, in which a significant imbalance between inbound and outbound flows of containers and the low frequency of liner services have been observed, but no studies on empty container repositioning have been conducted.

Table 2. Summary of relevant studies. Source: compiled by the authors.

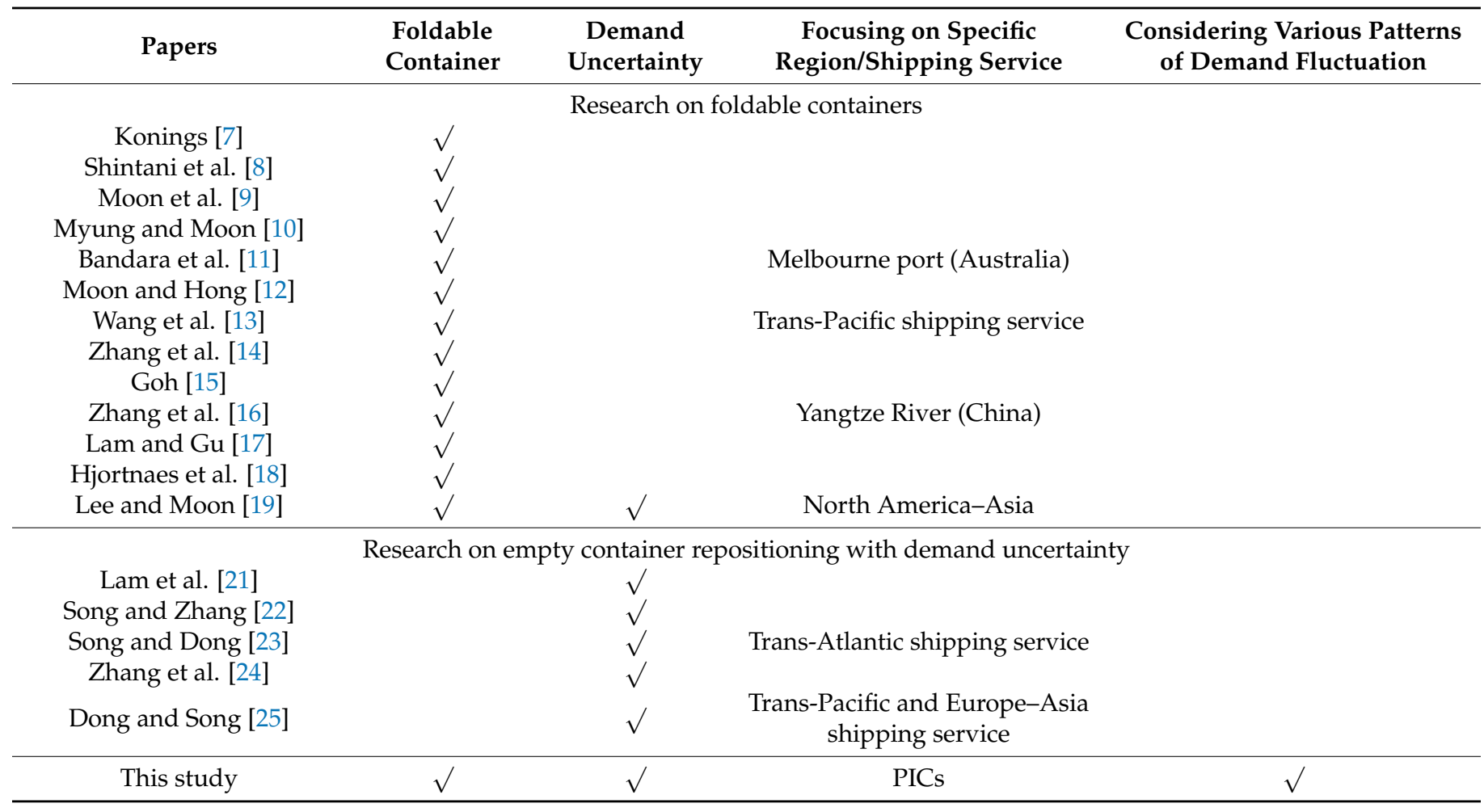




\section{Factors of Repositioning Empty Containers Considering Foldable Containers}

Based on the literature review, five factors that should be considered when analyzing the problem of maritime empty container repositioning with foldable containers are summarized in Figure 2. These comprise waiting time, empty container storage, vessel constraints, empty container flow, and container maintenance and repair.

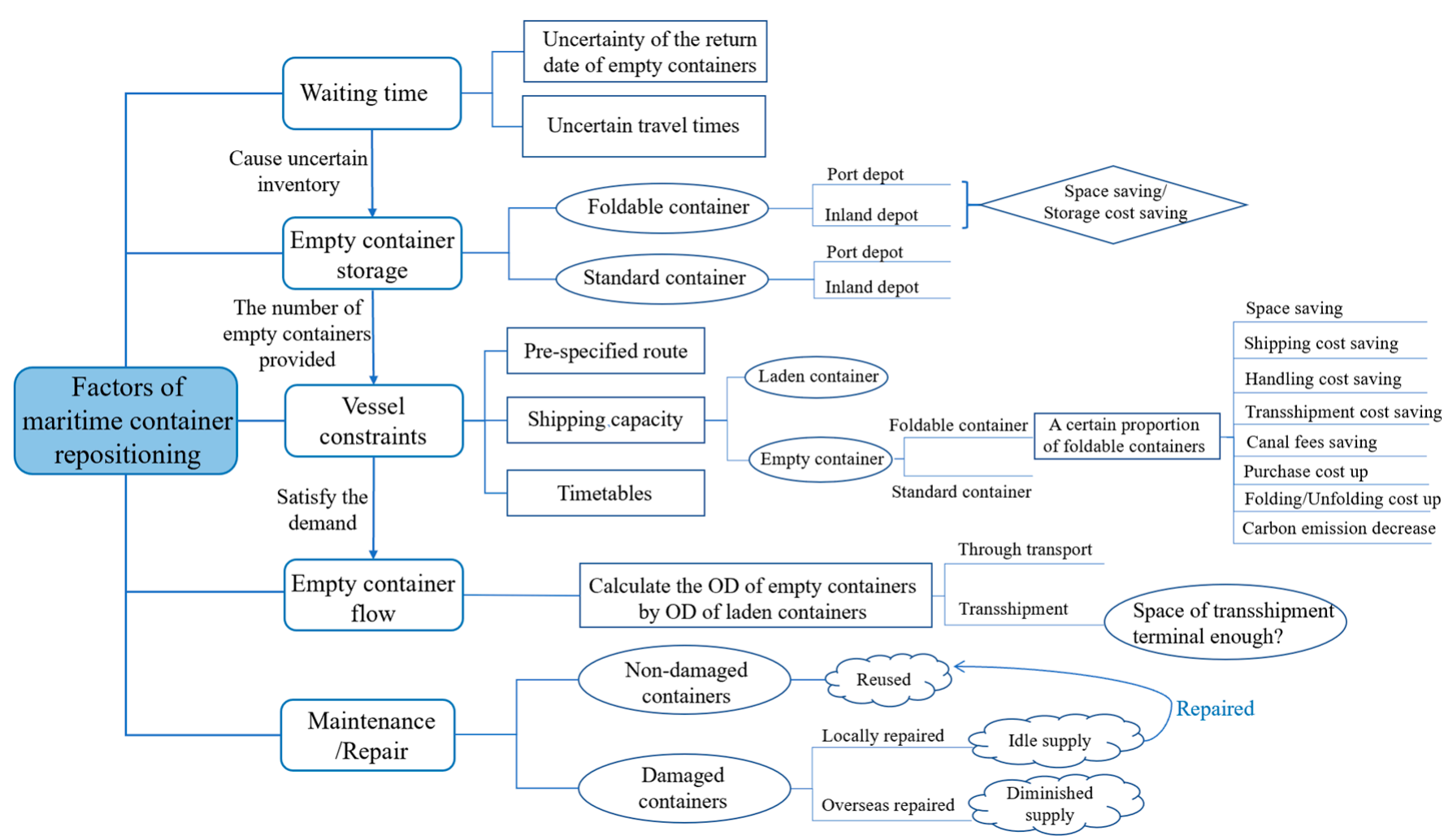

Figure 2. Factors of repositioning empty containers considering foldable containers. Source: compiled by the authors.

Empty containers generated in a particular region are stored in inland depots or returned to the ports, where they wait for a future cargo shipping demand, and a portion of these containers would be relocated to other ports to meet the demand for empty containers in other regions [26]. Compared with standard containers, more foldable containers can be stored in the same space if they are folded and bundled, thereby reducing the storage cost per unit. Uncertainty is a fundamental factor that impacts empty container repositioning, which may be caused by customer demands and container processing activities, such as consolidation, movement, handling, discharge, maintenance, and repair [27]. Owing to the uncertainty of the return date of empty containers and uncertain travel times due to adverse weather, there would be a corresponding uncertainty in the empty container inventory [28]. If a proportion of the empty containers in a certain period cannot be returned to the port in time, it would lead to a reduction of containers that can be repositioned in that period, resulting in unmet demand for the containers at some ports. Therefore, leased containers must be used, which incurs further fees [12]. In addition, uncertainties associated with fuel consumption, variation in vessel speed, fluctuating bunker fuel, and disruption (weatherrelated adversities or port closure) to container cargo shipping demand may affect the repositioning of empty containers [29,30]. Moreover, empty containers that cannot be repositioned will accumulate in the next period, resulting in a large number of empty containers to be repositioned. Containers must be carried by vessels, and their movements are subject to various constraints, such as the vessels' pre-specified routes, frequency, timetables, and carrying capacities. Empty container repositioning is further constrained by dynamic customer demands and vessels' spare capacities, because the shipping demand 
of these empty containers is determined to be similar to that of full containers that are prioritized for shipping [25]. Therefore, if the remaining space in the containership cannot afford the repositioning of all empty containers, the remaining empty containers would incur significant storage costs.

Foldable containers would deliver benefits if they can be bundled and transported together. As foldable containers in an empty state can be folded and bundled together to be stored in a specific place and repositioned as a single standard container, they will take up less space. Therefore, introducing foldable containers can reduce the risk of leaving a large number of empty containers that cannot be repositioned owing to demand fluctuations. Moreover, using less storage and shipping space can reduce storage and transport costs per unit. Cost savings can also be realized in transshipment costs if folded containers can be bundled, interlocked, and transshipped in one shipment [7,8]. However, if only repositioning containers is considered by a single liner service, the total maritime transport cost is fixed regardless of whether standard containers or foldable containers are used, and no transshipment costs are incurred. Furthermore, foldable containers can reduce the canal fees, which are determined by the height of the containers stacked on the deck of the ship [14]. However, transporting more containers also implies a higher load draft, which may not satisfy the corresponding limitation for some fairways. Hence, there is a tradeoff between the height above the water and draft when using foldable containers [16]. The impact of foldable containers would also extend to the environment, and studies have suggested that foldable containers could help in reducing the carbon footprint of the shipping industry $[11,15,17,18]$.

However, the disadvantages of foldable containers cannot be ignored. The exploitation/purchase cost is one of the barriers to using foldable containers, and additional costs are incurred when folding, unfolding, and handling foldable containers [20]. Moreover, the exploitation costs will be increased by higher maintenance and repair requirements. As the exploitation/purchase costs for foldable containers are much higher than those for standard containers, a mixed container fleet comprising both container types might be a viable option $[7,8]$. Such fixed costs in introducing foldable containers make it difficult to adjust the proportion of foldable containers depending on the situation; hence, the number (or rate) of foldable containers must be fixed in advance. Considering the significant increase in future cargo shipping demand, a large number of foldable containers needs to be introduced, which may lead to high costs. In this situation, the management costs of empty container repositioning may become cheaper by introducing another containership to increase service frequency, instead of introducing foldable containers.

In this study, because we aim to analyze the effect of introducing foldable containers for repositioning empty containers from an economic perspective, only four types of management costs are included in the analysis of the total management costs, for comparing with the scenario of using only standard containers; namely, storage costs for the safety stock of empty containers, the additional storage costs of empty containers that cannot be repositioned in time, purchase costs of foldable containers, and the costs of leasing containers to cover the shortage of empty containers at the ports with demand. Note that the voyage cost is not considered in this study, because in the case of repositioning empty containers by a single liner service, the total voyage cost is fixed regardless of whether foldable containers are used or not, and no transshipment costs are incurred. The terminal handling charge is also not included in this study, because we assume that the handling charge of foldable containers is the same as that of standard containers. 


\section{Problem Description and Formulation}

\subsection{Framework of the Problem}

This study focused on a monthly liner shipping service in the PICs (see Figure 3) and calculated the deficit or surplus of empty containers in ports, including Busan in South Korea, and Rabaul, Lae, and Port Moresby in Papua New Guinea, based on the number of containers loaded and discharged at each port in each period. There is a large demand for empty containers in Busan because it exports a large amount of containerized cargo. On the other hand, although there are containerized cargo export ports in the PICs, in the aggregate, containerized cargo is mainly imported, which implies that there is a surplus of empty containers in these ports. Further, the service frequency is low in these regions because of the low cargo shipping demand, resulting in a longer empty container repositioning period. The introduction of foldable containers can be expected to remedy the excess or deficiency of empty containers, as shipping companies are forced to reposition a large number of empty containers to ports of call to remedy the shortage.

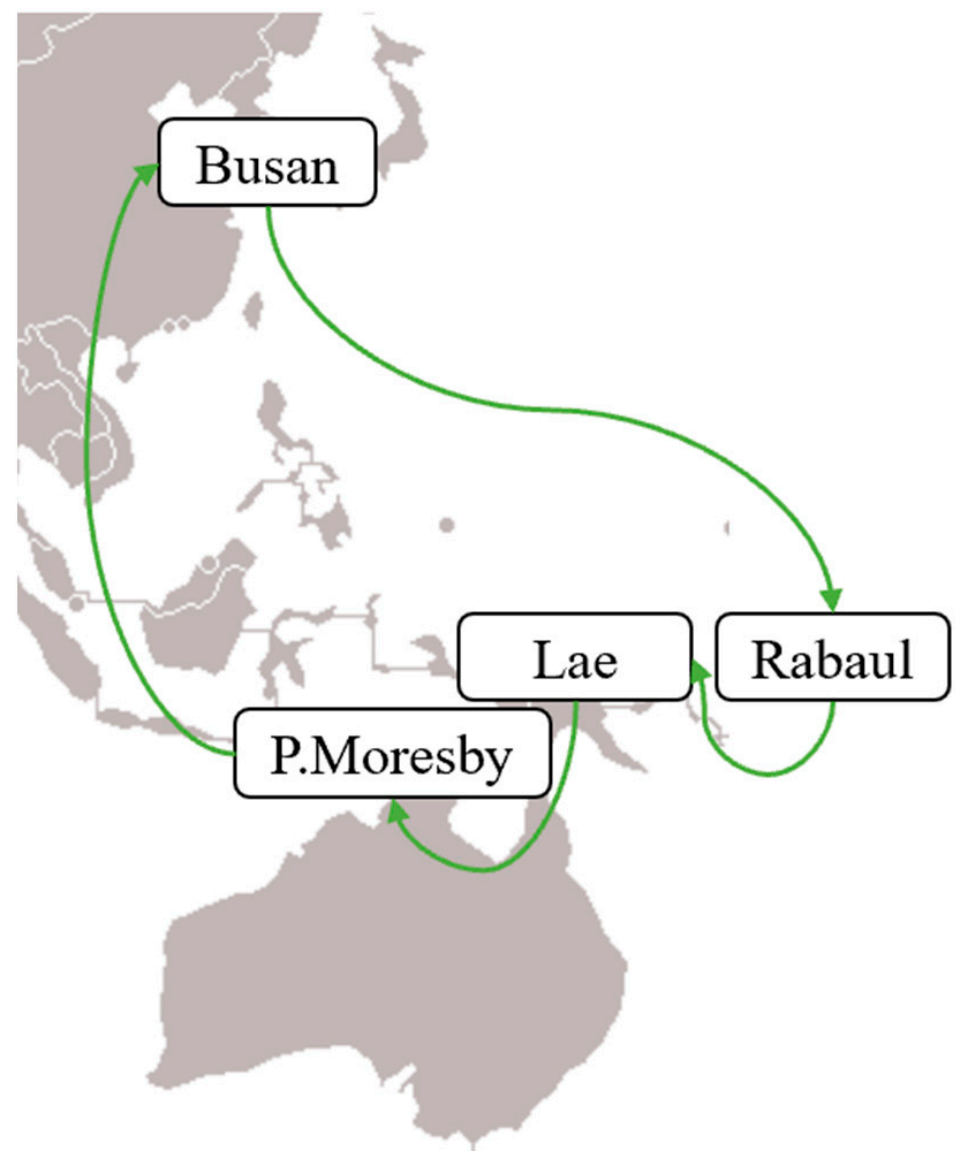

Figure 3. Papua New Guinea/Australia Service provided by Kyowa Shipping. Source: compiled by the authors, based on the Kyowa Shipping Co.

As mentioned in the previous sections, the shipping demand of containerized cargo generated at a port varies according to the shipping market conditions and seasons. Therefore, considering such demand fluctuations and analyzing various possible scenarios, including current and future demands, are necessary. Moreover, if container cargo shipping demand increases in the PICs, the frequency of the liner service will be doubled by introducing another containership, resulting in cheaper management costs for empty container repositioning. 
To reflect these characteristics, simulation of the empty container repositioning problem in the PICs would be conducted in two steps ("static analysis" and "consecutive analyses") to compare the total management costs of container repositioning of various patterns in different cargo shipping demand scenarios. In the static analysis, we would focus on one shipping period (i.e., for two months) and assume that container shipping demand is unchanged for each month, which corresponds to the average monthly shipping volume. In the consecutive analysis, a full year of cargo shipping demand is considered. As mentioned above, cargo shipping demand fluctuates depending on the season. Therefore, we assume that cargo shipping demand fluctuates per month, the sum of which is equal to the annual shipping volume. In this study, we assumed two different patterns of demand fluctuation. The first pattern is that the cargo shipping demand of each month fluctuates randomly, and the second is that it fluctuates in a biased manner.

This study compares the management costs of empty containers at different rates of introducing foldable containers. We also compare the cost of introducing another containership to increase service frequency, in cases where future cargo shipping demand would increase substantially. The other fundamental assumptions in the model calculation are as follows:

(1) The shipping volume of the full and empty containers cannot exceed the maximum capacity of the containership.

(2) If there is a shortage of empty containers at the port, leased containers are used for the shortage.

(3) If there are empty containers that cannot be repositioned, the storage fee is charged.

(4) Foldable containers were introduced in advance by a certain proportion.

(5) If foldable containers are introduced, the same number of standard containers is sold.

(6) Unused foldable containers are folded and stored at the port.

(7) The additional containership is used only if there are extra containers that cannot be shipped. Furthermore, even if another containership is introduced to increase service frequency, the annual container cargo shipping demand will not change.

(8) In the PIC maritime container shipping market, the basic transport cycle of containers is two months (a round trip on board of one month, and vanning/devanning and returning to the port of one month).

\subsection{Container Flow Estimation}

To analyze the empty container flow, the actual shipping volume of full containers for each liner service is necessary, but such data are generally not available for neutral researchers. Therefore, the annual volume of containerized cargo transported between each port for each liner service is calculated using the global maritime container shipping network simulation (GMCSNS) model, as shown in Riku et al. [6].

The GMCSNS model is a model in which the shipping route of each container is determined by the global interregional maritime container cargo shipping demand (OD volume) and maritime network factors, such as service frequency and vessel capacity [31,32]. Congestion would also occur if the capacity of the containership approached the upper limit. In the GMCSNS model, the liner shipping services operated by each container shipping company are treated as a separate network, as shown on the right side of Figure 4. In this study, the number of empty containers that are generated or in demand is assumed to be the difference between the volume of loading and discharging cargo (discharging volume-loading volume) generated at a port in the previous period. In principle, the shipping company meets the demand for empty containers with those that are transported using the extra spaces on board. The outputs of the GMCSNS model are on an annual basis, so in this study, we converted them to a monthly basis. Figure 5 shows an empty container repositioning plan (on average), where the black arrows represent the full container flow, and the blue arrows represent the empty container flow. 

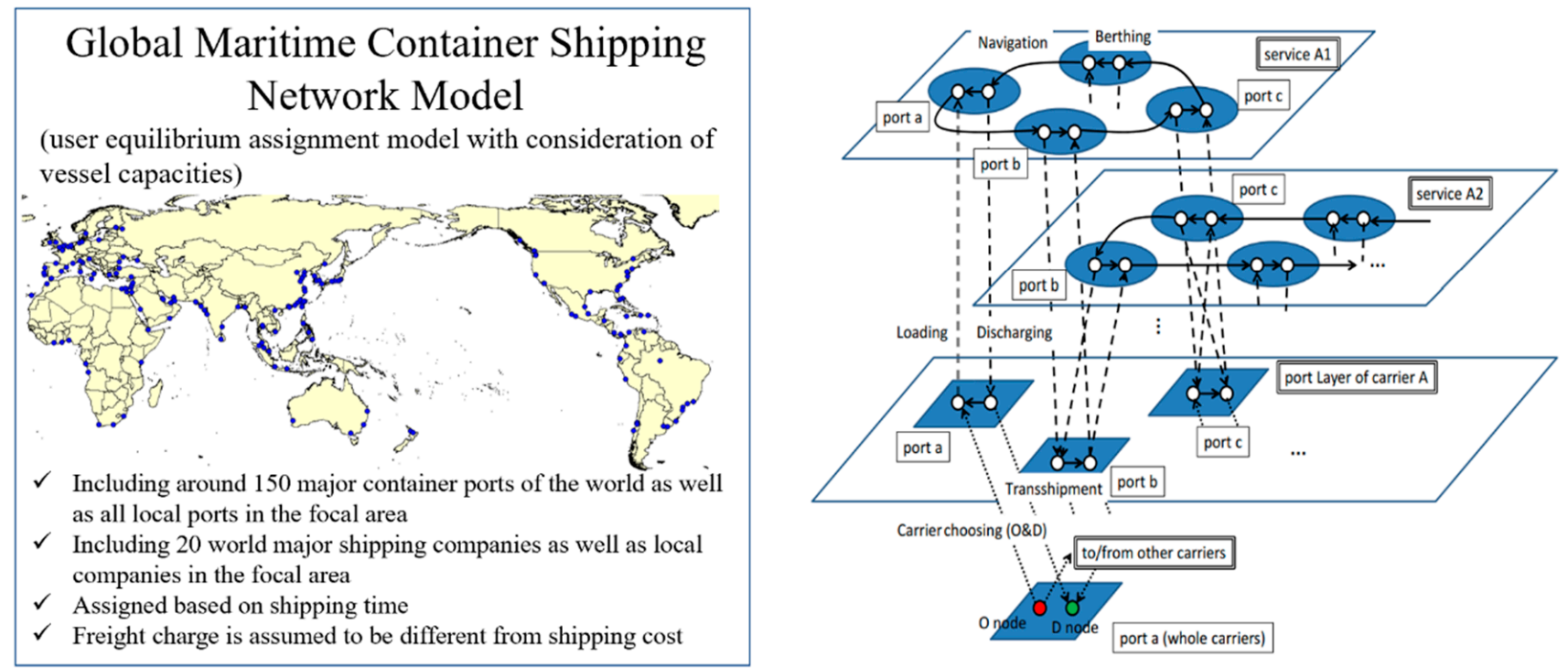

Figure 4. Network structure of the maritime container shipping network model. Source: Shibasaki [31].

Capacity of the containership: 506 TEU

Frequency of the service: 1 shipping/month

98

Port Name

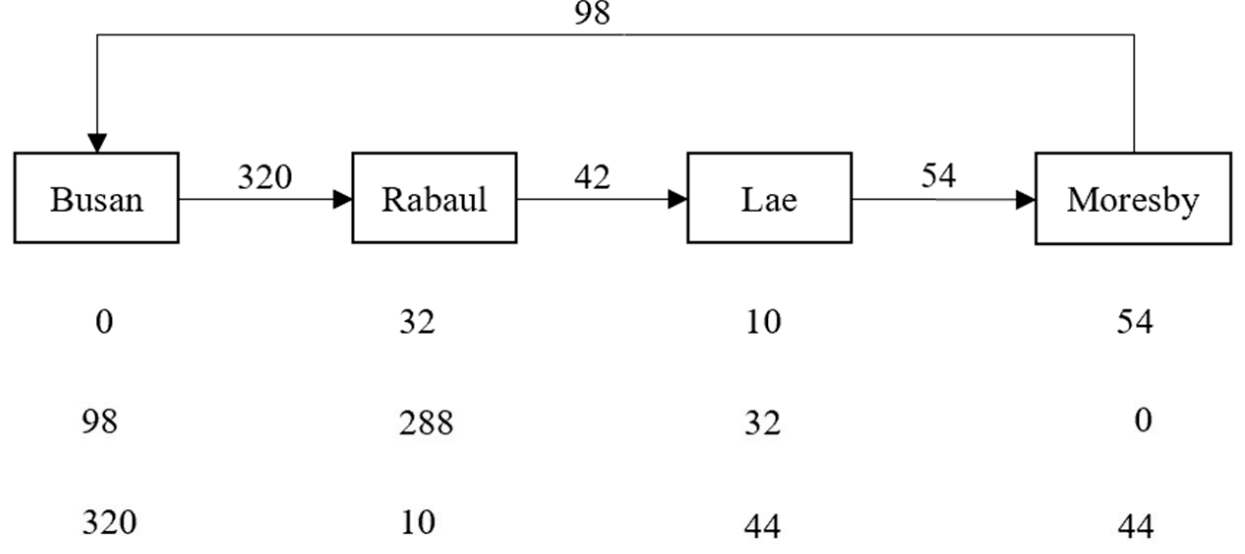

Anchoring (TEU)

178

Empty Containers (TEU)
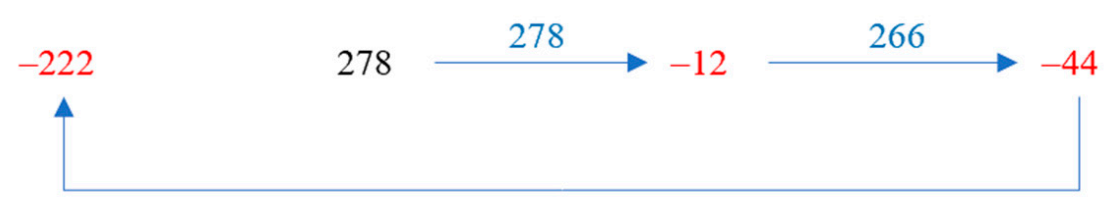

222

Laden Containers Flow

Empty Containers Flow

Figure 5. Empty container repositioning plan. Source: compiled by the authors.

\subsection{Formulations}

\subsubsection{Volume of Empty Containers}

Repositioning empty containers from the surplus to deficit areas is necessary to ensure the balance between the inbound and outbound flows of full containers. In other words, the shipping demand of empty containers depends on the shipping pattern of full containers [1] Some empty containers generated two months ago may not have been repositioned in the previous month. Therefore, the empty container repositioning demand of this month is the sum of the empty containers generated in the previous month and the surplus of 
empty containers in the previous month. The volume of empty containers in this month is expressed by the following equation:

$$
R_{t}=E_{t-1}+\gamma \cdot E_{t-2}
$$

where $R_{t}$ is the empty container repositioning demand (twenty-foot equivalent unit, or TEU) in period $t, E_{t}$ is the volume of empty containers (TEU) generated in period $t$, and $\gamma$ is the surplus rate of empty containers in the previous period.

As maritime container shipping demand fluctuates with the seasons, the volume of empty containers generated varies accordingly. Therefore, the volume of empty containers is not necessarily the monthly average value in some scenarios. The volume of empty containers generated in the previous period is represented by Equation (2).

$$
E_{t}=\bar{E} \cdot\left(1+\alpha_{t}\right),
$$

where $\bar{E}$ is the average shipping demand of empty containers (TEU), and $\alpha_{t}$ is the demand change rate in period $t$.

In principle, the demand for empty container repositioning should be met by the remaining space of the containership, after satisfying the shipping demand for full containers. As described in Section 1, the PICs have few domestic industries aside from agriculture and fishery, and rely heavily on imported goods $[5,6]$. If their industrial structure and trade construction remain unchanged, the balance of imports and exports would not change even if the total volume of cargo shipping demand changes. Therefore, the volumes of loading and discharging cargo are assumed to change at the same rate in this study, and the variation of full and empty container volumes can be represented by the same value of $\alpha_{t}$. Moreover, the number of empty containers that can be repositioned from a port is restricted by the remaining space of the ship after loading full containers at the port [8], which is expressed in Equation (3).

$$
S_{t}=V-\bar{X} \cdot\left(1+\alpha_{t}\right),
$$

where $S_{t}$ is the remaining space of the ship (TEU) in period $t, V$ is the capacity of the containership (TEU), and $\bar{X}$ is the average shipping demand of full containers (TEU).

In the following formulas, as stated in Section 3, we consider four types of management costs of maritime empty container repositioning.

\subsubsection{Standard Containers Only}

In the case of using only the standard container, if the empty container repositioning demand is less than the remaining space of the ship, because all the empty containers can be repositioned in the current period, we only consider the storage cost of the standard container. If the empty container repositioning demand is greater than the remaining space of the ship, some empty containers cannot be repositioned in the current period. Because the basic transport cycle of containers is two months, the container inventory at the port should subtract the number of containers that are shipped to other ports in the current period and in the previous period. Therefore, the storage costs and rental fees of those containers that cannot be repositioned should also be considered as follows:

$$
\begin{gathered}
C_{t}=\left[S D-\bar{X} \cdot\left(1+\alpha_{t-1}+1+\alpha_{t}\right)\right] \cdot C S, \text { if } R_{t} \leq S_{t}, \\
C_{t}=\left[S D-\bar{X} \cdot\left(1+\alpha_{t-1}+1+\alpha_{t}\right)\right] \cdot C S+\left(R_{t}-S_{t}\right) \cdot(C S+C L), \text { if } R_{t}>S_{t},
\end{gathered}
$$

where $C_{t}$ is the total management cost (US\$), $S D$ is the total number of standard containers (TEU), CS is the container storage cost per TEU (US\$/TEU), and CL is the container rental fee per TEU (US\$/TEU). 


\subsubsection{Introducing Foldable Containers}

After the introduction of foldable containers, three foldable containers can be folded into the equivalent of a standard container to reposition the empty containers, enabling the space of the containership to be fully used while more empty containers can be repositioned.

If the empty container repositioning demand is greater than the remaining space of the ship, we can use a certain number of foldable containers to satisfy the demand of empty containers to be equal to or less than the remaining space, as expressed in Equation (6).

$$
\left(R_{t}-F_{t}\right)+\frac{F_{t}}{3} \leq S_{t} \text {, if } R_{t}>S_{t},
$$

where $F_{t}$ is the demand for foldable containers (TEU) in period $t$. Therefore, the minimum demand for foldable containers is represented by Equation (7).

$$
F_{t}=\frac{3}{2} \cdot\left(R_{t}-S_{t}\right)
$$

If the empty container repositioning demand is less than the remaining space of the containership, all empty containers can be repositioned without using a foldable container; that is,

$$
F_{t}=0 \text {, if } R_{t} \leq S_{t} .
$$

If the demand for foldable containers is less than the number of foldable containers that are introduced, all the repositioning demand of empty containers can be met by substituting standard containers with the same quantity of foldable containers. In addition, unused foldable containers can save storage space and contribute to storage cost reduction. In this case, the storage cost of a foldable container is only one-third that of the standard container, because it takes up one-third of the space of the standard container by using the 3-in-1 foldable container.

$$
C_{t}=\beta \cdot S D \cdot C D+C F O+\left((1-\beta) \cdot S D-\bar{X} \cdot\left(1+\alpha_{t-1}+1+\alpha_{t}\right)\right) \cdot C S+\left(\beta \cdot S D-F_{t}\right) \cdot \frac{C S}{3}, \text { if } F_{t} \leq \beta \cdot S D,
$$

where $\beta$ is the introduction rate of foldable containers, $C D$ is the purchase cost of foldable containers (US\$/TEU), and CFO is the fixed cost (US\$) of introducing foldable containers.

However, under the condition that the foldable containers are introduced in advance in a certain proportion, if the demand for foldable containers is greater than the number of foldable containers that are introduced, foldable containers can only alleviate the problem of insufficient capacity to a certain extent, and there would still be empty containers that cannot be repositioned. In this case, the storage fees for the empty containers that cannot be repositioned and the cost of renting leased containers to cover the shortage of empty containers would be incurred, as expressed below:

$$
C_{t}=\beta \cdot S D \cdot C D+C F O+\left((1-\beta) \cdot S D-\bar{X} \cdot\left(1+\alpha_{t-1}+1+\alpha_{t}\right)\right) \cdot C S+\left(R_{t}-\beta \cdot S D \cdot \frac{2}{3}-S_{t}\right) \cdot(C S+C L), \text { if } F_{t}>\beta \cdot S D \text {. }
$$

\section{Static Analyses}

Initially, we focused on one shipping period (i.e., for two months) and calculated management costs. For the calculation, we assumed that there is a case where half of the empty containers generated in the previous period cannot be returned to the port in time (i.e., $\gamma=0.5$ ). Moreover, we assumed the following scenarios: the shipping company possesses $1200 \mathrm{TEU}$ standard containers for this service (i.e., $S D=1200$ ); container storage and leasing fees per month per container are 200\$US and 300\$US, respectively (i.e., $C S=200$ and $C L=300)$; the purchase cost of a foldable container is 3000\$US/TEU with 10 years' lifespan (i.e., $C D=300$ ); and the fixed cost for introducing foldable containers is $1,200,000 \$$ US with 10 years' lifespan (i.e., $C F O=120,000$ ), based on the previous studies $[2,7,8,33]$, with adjustments for considering the maritime shipping and container market in the PICs and the more advanced foldable containers used in this study [2]. Specifically, the container storage fee is assumed to be lower than those in previous studies because 
the land price is lower in the PICs. Further, the purchase and fixed cost of the foldable containers were assumed to be higher because of their more advanced design as considered in this study.

\subsection{Container Cargo Shipping Demand with Smaller Increasing Rate}

Figure 6 shows the total management costs of empty container repositioning in the current average cargo shipping demand, as indicated in Figure 5 (i.e., $\alpha_{t-1}=\alpha_{t}=0$ ), as well as those in which the cargo shipping demand is increased to some extent (i.e., $\alpha_{t-1}=\alpha_{t}=0.1,0.15,0.2,0.25,0.3$, and 0.35), with several scenarios on the introduction rate of foldable containers, namely, $\beta=0$ (scenario S0, standard containers only), $\beta=0.05$ (S1), $\beta=0.1$ (S2), and $\beta=0.15$ (S3). As shown in the figure, the total management cost first decreases as cargo shipping demand increases in each scenario on the introduction rate of foldable containers, because the storage cost decreases as cargo shipping demand increases. However, it gradually increases if cargo shipping demand becomes greater than a certain level, because the rental fee of leased containers significantly increases due to a shortage of available containers.
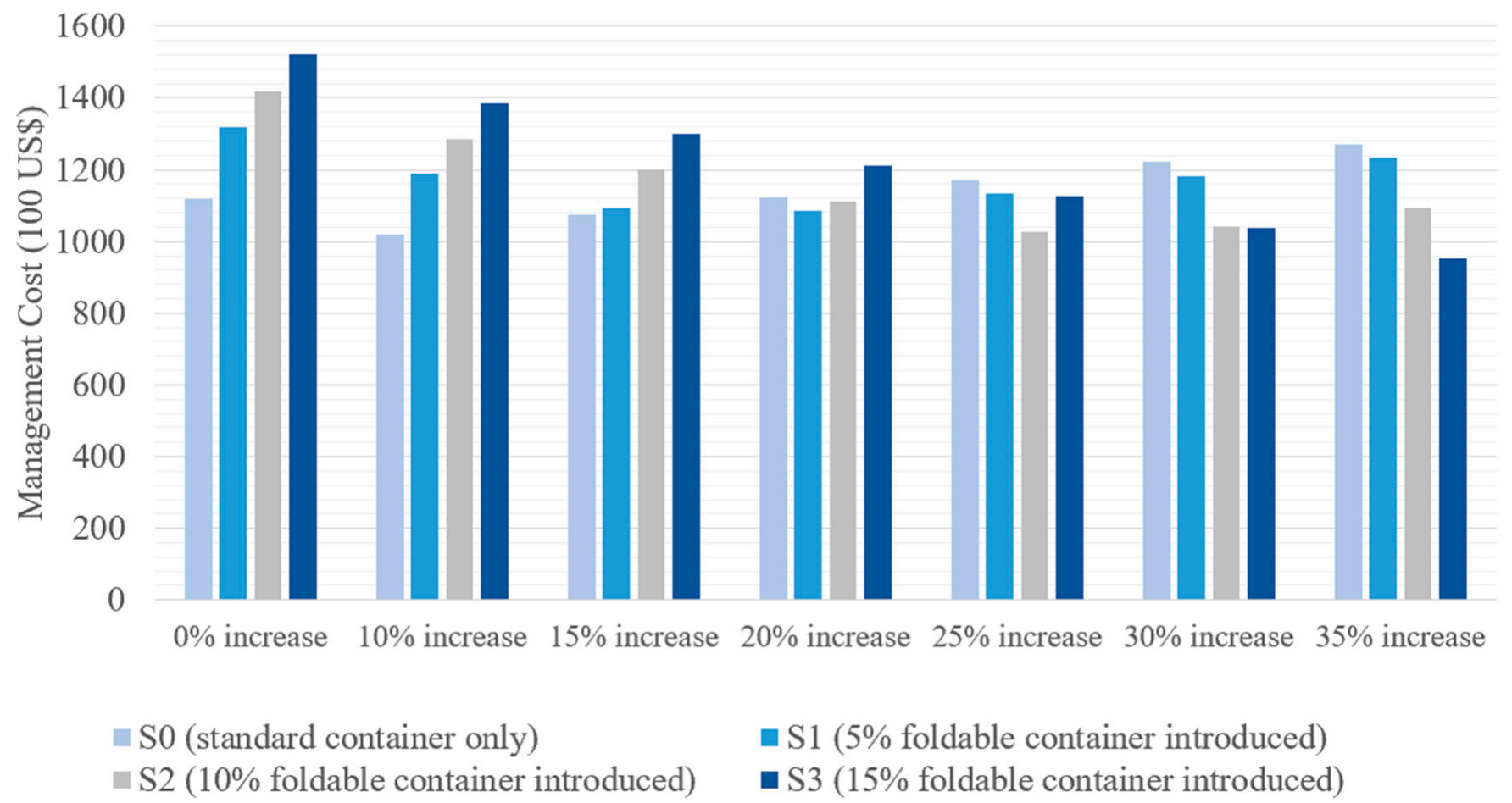

Figure 6. Total management cost of empty container repositioning in the current cargo shipping demand and smaller demand increase scenarios (standard containers only vs. foldable containers introduced). Source: compiled by the authors.

As shown in Figure 6, at the current average cargo shipping demand, or with a slight increase in the cargo shipping volume $\left(\alpha_{t-1}=\alpha_{t}=0,0.1\right.$ and 0.15$)$, the total management costs of empty container repositioning are the cheapest if only standard containers are used (S0). In other words, it is better not to introduce foldable containers because there is enough space on the containership to reposition empty containers, owing to the small shipping volume of full and empty containers. If the cargo shipping demand increases by $20 \%$, by introducing $5 \%$ of foldable containers (S1), management costs would be minimized. Moreover, the introduction of $10 \%$ of foldable containers (S2) could reduce the management costs compared to using standard containers only. However, it is more expensive than S1. This implies that foldable containers may be effective in reducing the cost of managing empty containers. Meanwhile, with the introduction of $15 \%$ of foldable containers (S3), the total management cost is higher than that of S0 (using only standard containers), which 
implies that introducing too many foldable containers would increase management costs. If cargo shipping demand increases by $25 \%$, S2 has the greatest effect on cost reduction. If it increases by $30 \%$ or more, S3 would be more economically effective.

Furthermore, because the effect of introducing foldable containers in reducing management costs is greatly influenced by the related costs of foldable containers, if the related costs of foldable containers exceed a certain range- the threshold-any empty container management costs after introducing any proportions of foldable containers would not be lower than that in S0 (using only standard containers). By calculating the thresholds on purchase cost $C D$ and the fixed cost CFO of foldable containers under different cargo shipping demands, it is found that the threshold increases as cargo shipping demand increases, as shown in Figure 7. If the purchase and fixed costs exceed the threshold of the " $35 \%$ increase of demand" area, foldable containers would lose their advantage, regardless of the cargo shipping demand and proportion of foldable containers. Note that if the increasing rate of cargo shipping demand is $0 \%, 10 \%$, and 15\%, introducing foldable containers in any proportions would be more expensive than $\mathrm{S} 0$ under the minimum condition on these costs (i.e., $C D=300$ and $C F O=120,000$ ), as shown in Figure 6.

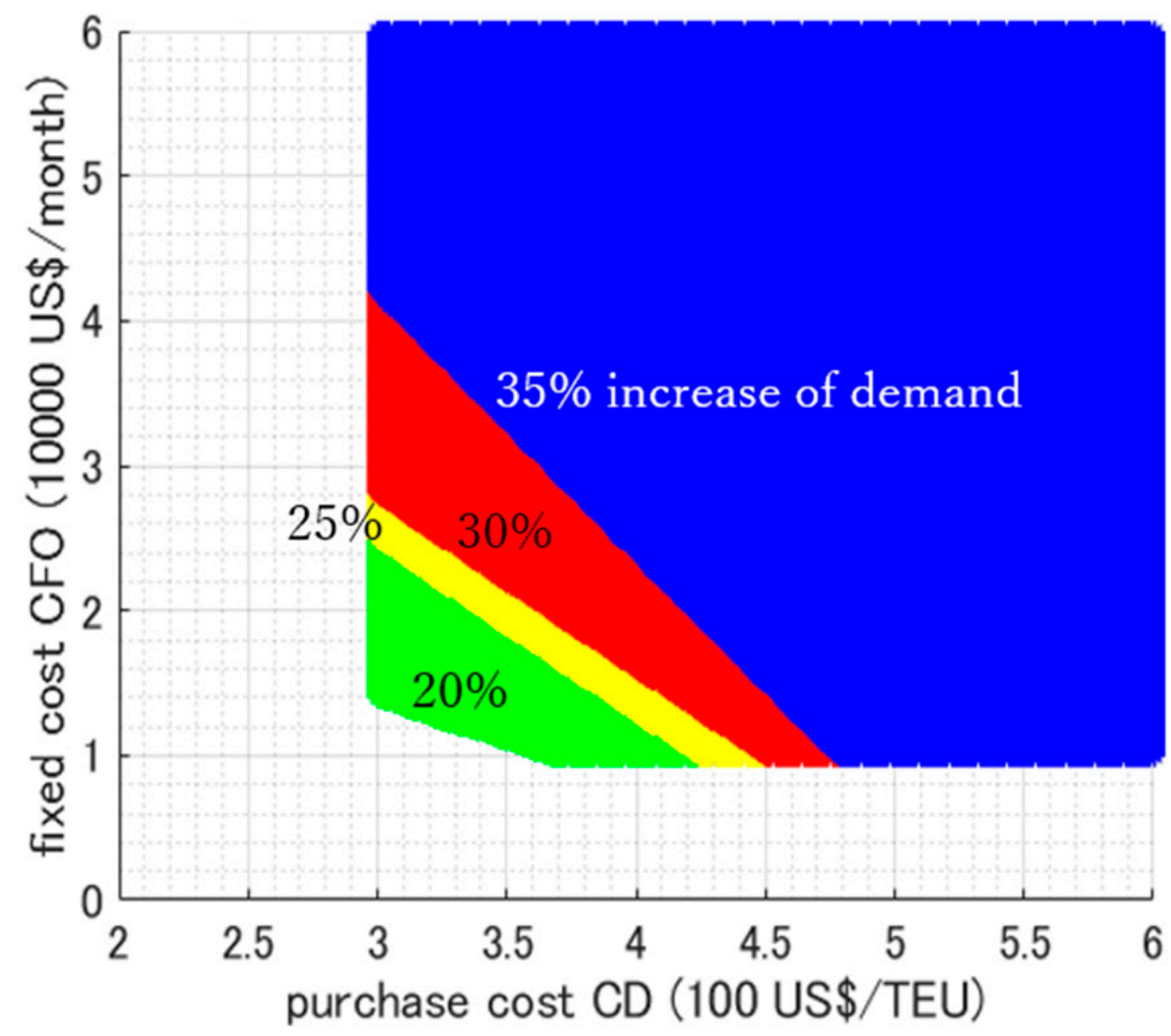

Figure 7. Thresholds of purchase and fixed costs of foldable containers by cargo shipping demand (with smaller increasing rate) at which foldable containers lose their advantage against the scenario of only standard containers. Source: compiled by the authors.

\subsection{Container Cargo Shipping Demand with Higher Increasing Rate}

In future scenarios, we assumed that the total number of standard containers possessed by a shipping company is 1500 TEU (i.e., $S D=1500$ ), to meet the future cargo shipping demand when $\alpha_{t-1}=\alpha_{t}=0.45,0.5,0.55$, and 0.6 . Considering the increase in future cargo shipping demand in PICs, the management costs of empty container repositioning may become cheaper by introducing another containership. In this case, additional maritime shipping costs should be considered as well as the total management costs of empty container repositioning, as incorporated in the previous section. In this study, we calculated the maritime container shipping cost, which consists of 
the fuel cost, capital cost, and operation cost, based on the formulations in the GMCSNS model [31,32]. Figure 8 illustrates the total management costs of empty container repositioning for each scenario on the introduction rate of foldable containers, i.e., $\beta=0$ (S0), $\beta=0.15(\mathrm{~S} 3), \beta=0.2(\mathrm{~S} 4), \beta=0.25$ (S5), and $\beta=0.3(\mathrm{~S} 6)$, as well as the scenario with introducing another containership without any foldable containers (S7). The figure also indicates that introducing foldable containers and another containership can significantly reduce costs, compared to S0 (using only standard containers). More specifically, if the cargo shipping demand increases by $45-55 \%$, it is more economical to introduce $20 \%$ of foldable containers (S4), whereas, if the cargo shipping demand increases by $60 \%$, S7 (adding another containership) would be the optimal option. We also calculated the thresholds at which introducing foldable containers (fld) would be more expensive than S0 and S7, as shown in Figure 9. The figure indicates that the thresholds are lower when compete with $\mathrm{S} 7$ than $\mathrm{S} 0$, regardless of the increasing rate of cargo shipping demand. In other words, the "fld $>\mathrm{S} 0$ " area is completely encompassed by the "fld > S7" area. If the purchase and fixed costs of foldable containers exceed the threshold of the "fld > S7" area, foldable containers would lose their advantage in competition with introducing another containership, whichever the increasing rate is between $45 \%$ and $60 \%$ of cargo shipping demand and proportion scenarios of foldable containers. Further, it is found that the threshold of "fld > S7" decreases as cargo shipping demand increases, whereas that of "fld > S0" increases. Note that if the increasing rate of cargo shipping demand is $60 \%$, introducing foldable containers in any proportions would be more expensive than $\mathrm{S} 7$ under the minimum condition on these costs (i.e., $C D=300$ and $C F O=120,000$ ), as shown in Figure 8.

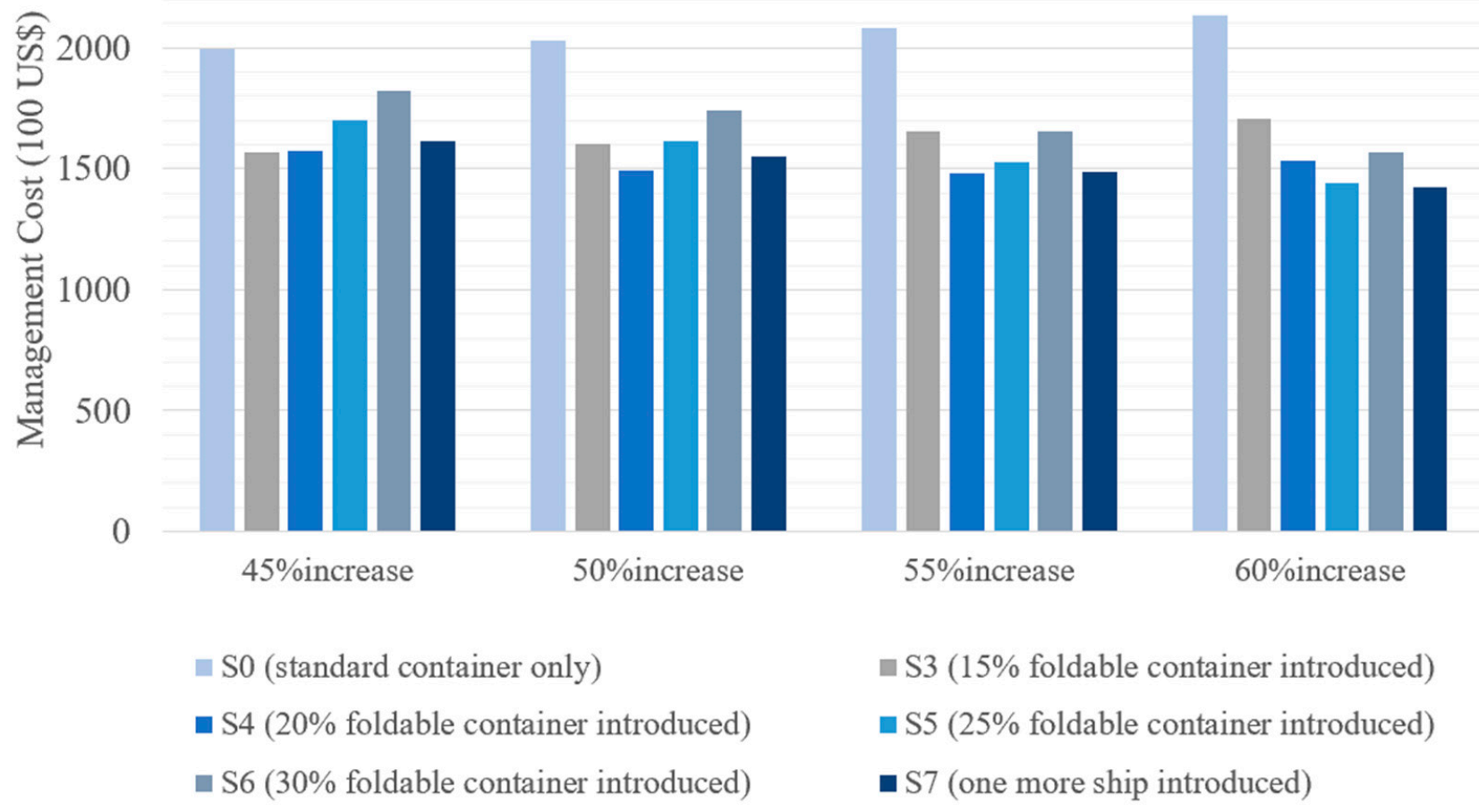

Figure 8. Total management cost of empty container repositioning in the future cargo shipping demand scenarios (standard containers only vs. foldable containers introduced vs. one more ship). Source: compiled by the authors. 
$45 \%$ increase of demand

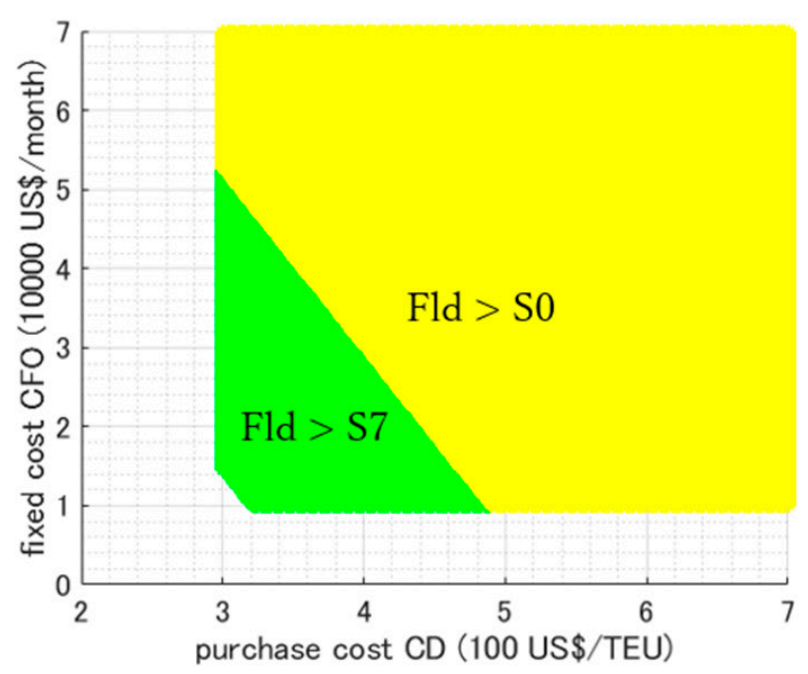

$55 \%$ increase of demand

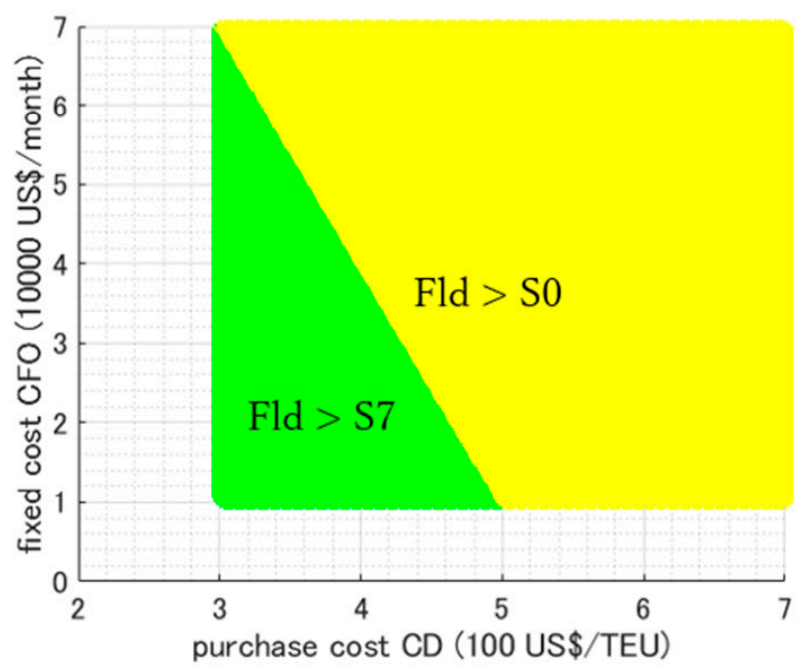

$50 \%$ increase of demand

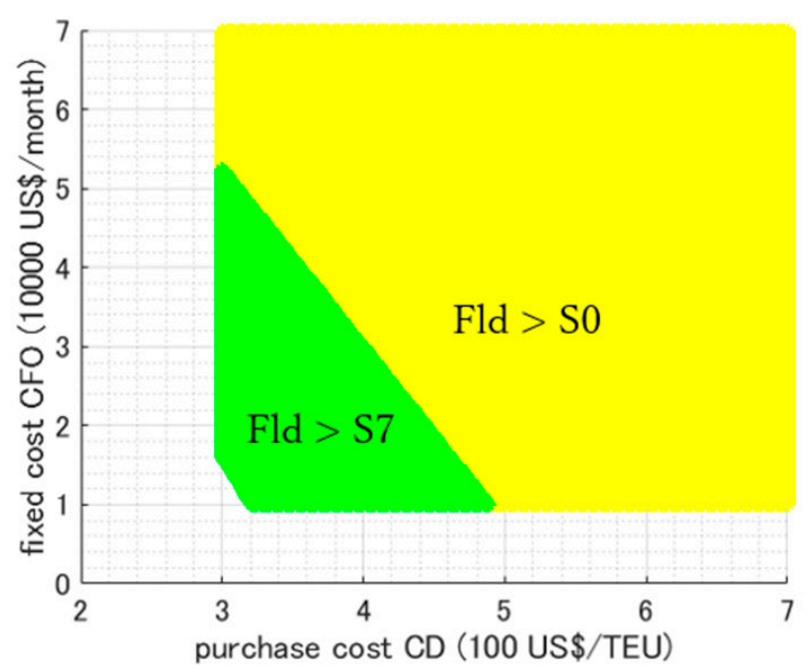

$60 \%$ increase of demand

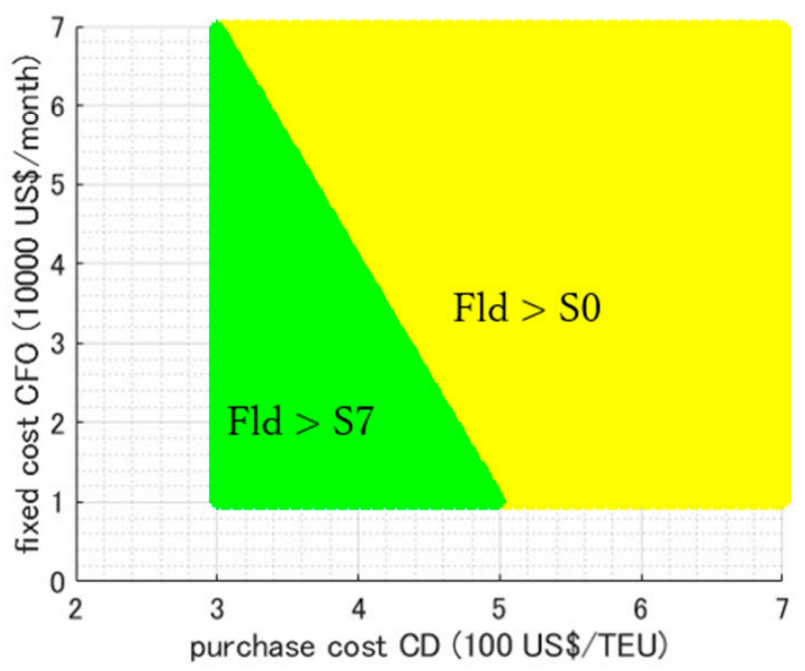

Figure 9. Thresholds of purchase and fixed costs of foldable containers by cargo shipping demand (with higher increasing rate) at which foldable containers lose their advantage against the only standard containers and one more ship introduced scenarios. Source: Compiled by the authors.

\section{Consecutive Analyses with Demand Fluctuation}

As described in Section 4, cargo shipping demand fluctuates seasonally. In this section, we assume that cargo shipping demand fluctuates from month to month, the sum of which is equal to the annual shipping volume given. In the following consecutive analyses, we assumed two different approaches to generating scenarios on demand fluctuation. The cargo shipping demand of each month (1) fluctuates randomly and (2) fluctuates biasedly. The second approach (biased demand) is necessary to consider because the actual cargo shipping demand is seasonally biased [4], and we assume in this study that the cargo shipping demand of each month in the first half-year is lower than average demand and that of each month in the second half of the year is higher than the average demand. Unlike in Section 5, here, all the empty containers generated in the previous period can be 
returned to the port in time (i.e., $\gamma=0$ ). However, in case that cargo shipping demand is consecutively high for several months, some empty containers may have accumulated for a long period of time.

We randomly generated 1000 different one-year consecutive scenarios on monthly cargo shipping demand, depending on each given future cargo shipping demand (i.e., $\overline{\alpha_{t}}=0.2,0.3,0.4$, and 0.5. $\overline{\alpha_{t}}$ is the annual average cargo shipping demand growth rate), and then the management costs of empty container repositioning for each scenario were calculated. We set the ranges of consecutive shipping demand for each approach (random and biased demand) by annual average demand growth rate and randomly generated monthly demand with the same probability within the range. Table 3 summarizes the ranges on the cargo shipping demand from Busan to Rabaul for each approach, by annual average demand growth rate (note that the demands in other maritime shipping links are set proportionally to them). Figures 10 and 11 also show examples of generated consecutive shipping demand from Busan to Rabaul for both approaches. As shown in Table 3, we set the maximum value to be slightly less than the vessel capacity (506 TEU), and the minimum value to ensure that the sum of cargo shipping demand throughout a given year is equal to the annual shipping volume, considering demand growth. In the case of biased demand, we assumed that the cargo shipping demand is lower in the first half-year and higher in the second half-year. Unlike the static analysis in the previous section, which is assumed to occur from the beginning of the calculation, the delayed return of empty containers is assumed to occur in this section only if the demand for empty container repositioning becomes more than the vessel capacity in the consecutive calculations. This is the reason the introduction of an additional ship was not efficient in any scenario in this section (therefore, they were not included in the following analyses).

The management costs of empty container repositioning were calculated for each scenario, and the cases were compared to use only standard containers and to introduce foldable containers. As shown in Figure 12, the probability that the management cost of introducing foldable containers is lower than that when using only standard containers increases (S0) as the cargo shipping demand increases in both random and biased demand patterns. Moreover, in the case that the demand fluctuation is biased, it is more likely that introducing foldable containers has a greater effect on cost reduction than in the case of random demand, if they are compared using the same annual average growth rate of cargo shipping demand. This is because the continuous high cargo shipping demand in the second half of the year would lead to the accumulation of large numbers of empty containers, resulting in a significant increase in management costs. Therefore, the use of foldable containers can alleviate the accumulation of empty containers, and then enhance the more efficient use of containers and the sustainability of the shipping industry. In addition, the results shown in the figure imply that there may be an optimal introduction rate of foldable containers, because the probability that the cost of introducing $20 \%$ foldable containers (S4) at its lowest is higher than that of introducing 30\% foldable containers (S6).

Table 3. Ranges set for random and biased container shipping demand by annual average demand growth rate, in case of the demand from Busan to Rabaul. Source: compiled by the authors.

\begin{tabular}{cccccccc}
\hline \multirow{2}{*}{$\begin{array}{c}\text { Annual Average Container Shipping } \\
\text { Demand Growth Rate } \overline{\alpha_{t}}\end{array}$} & \multicolumn{2}{c}{$\begin{array}{c}\text { Random Demand Scenario } \\
\text { (TEU/Month) }\end{array}$} & \multicolumn{3}{c}{ Biased Demand Scenario (TEU/Month) } \\
\cline { 2 - 7 } & \multicolumn{2}{c}{ Min } & Max & Mirst Half Year & \multicolumn{2}{c}{ Second Half Year } \\
\hline 0.2 & 180 & 480 & 180 & 330 & 330 & 480 \\
\hline 0.3 & 200 & 480 & 200 & 340 & 340 & 480 \\
\hline 0.4 & 230 & 490 & 230 & 360 & 360 & 490 \\
\hline 0.5 & 250 & 490 & 250 & 370 & 370 & 490 \\
\hline
\end{tabular}




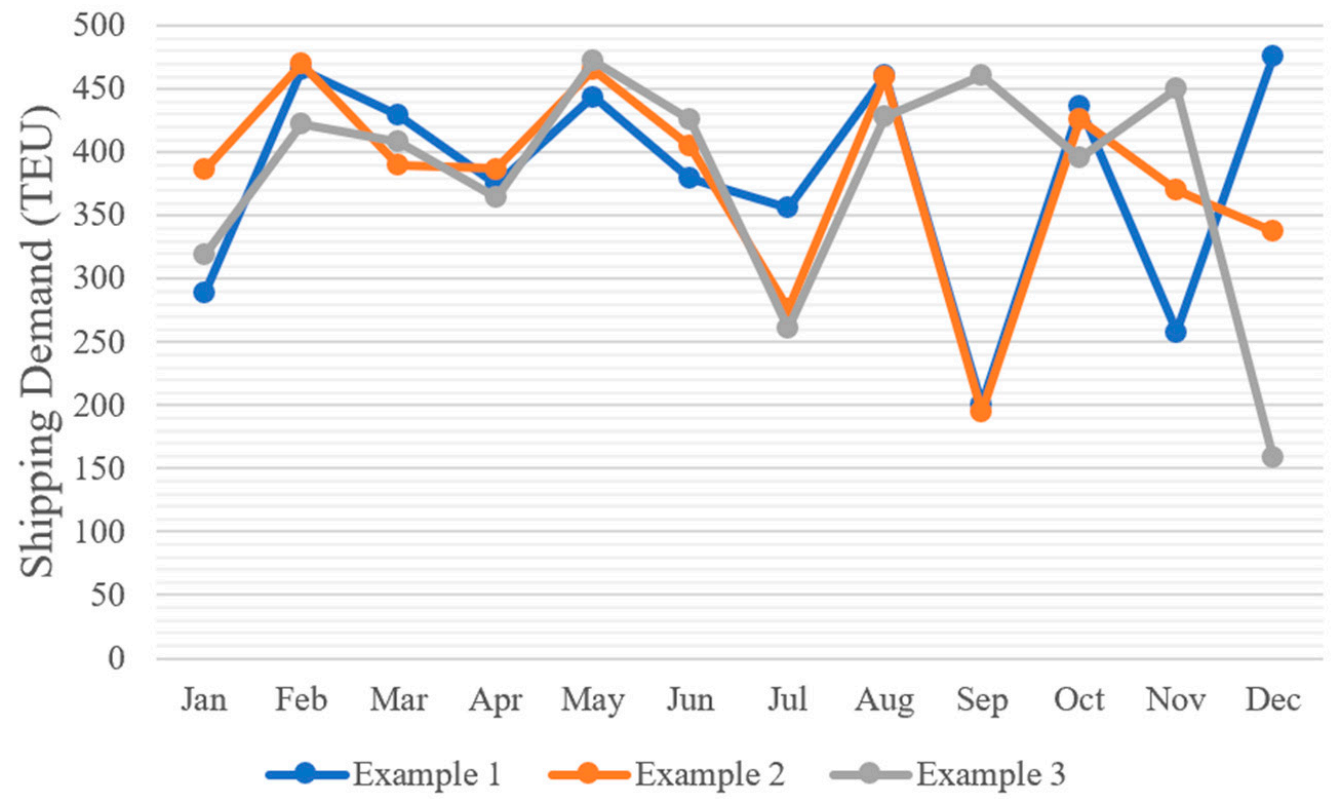

Figure 10. Examples of consecutive cargo shipping demand from Busan to Rabaul in the random fluctuation approach $\left(\overline{\alpha_{t}}=0.2\right)$. Source: compiled by the authors.

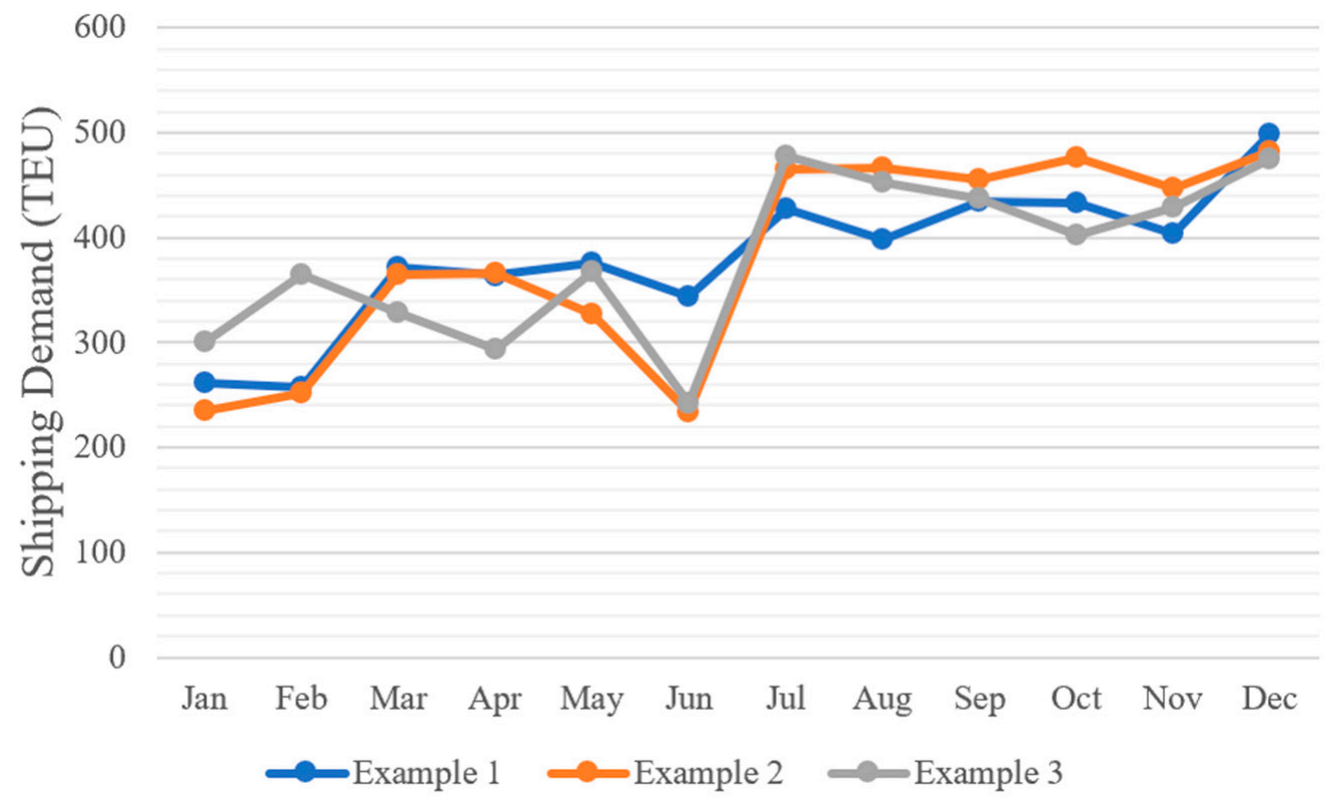

Figure 11. Examples of consecutive cargo shipping demand from Busan to Rabaul in the biased fluctuation approach $\left(\overline{\alpha_{t}}=0.2\right)$. Source: compiled by the authors. 
Demand in random fluctuation approach

Demand in biased fluctuation approach

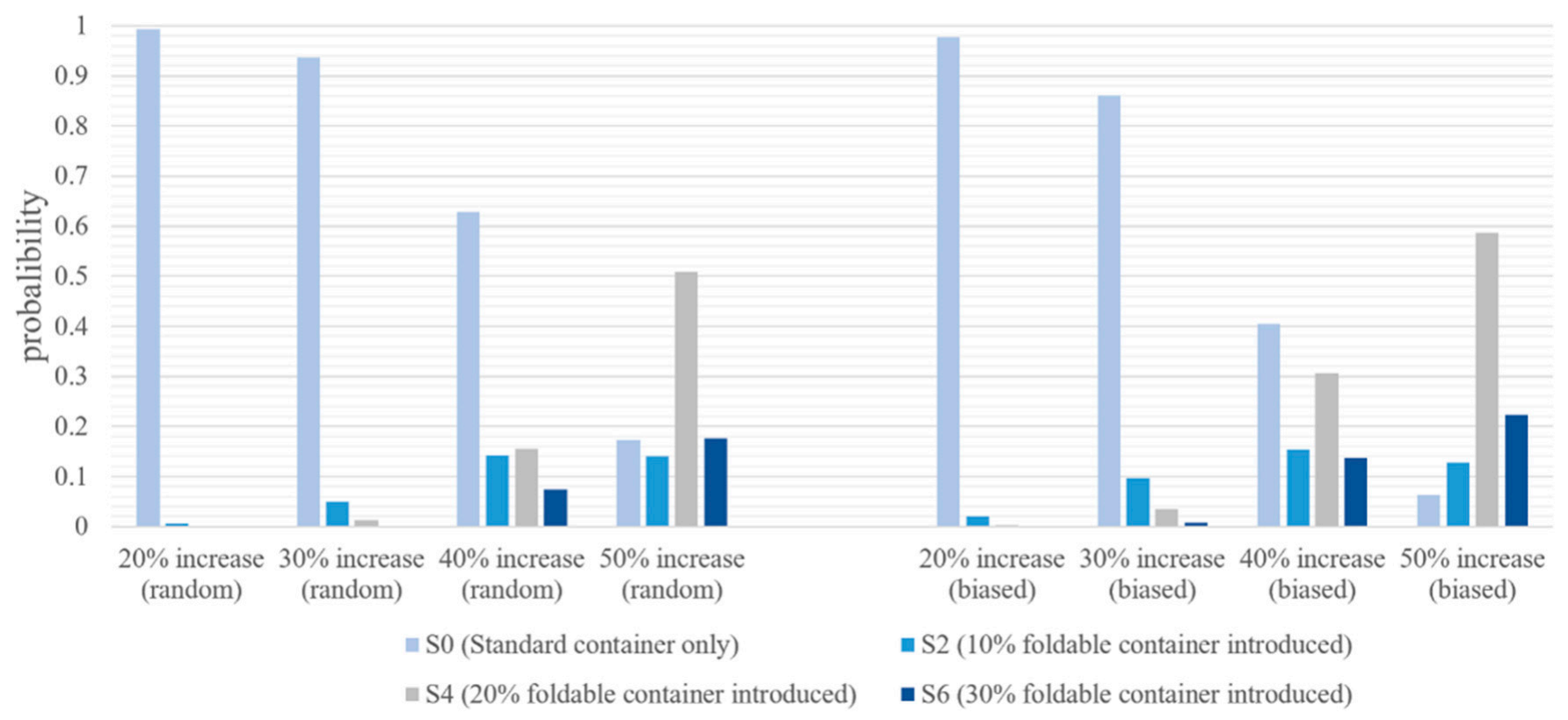

Figure 12. Probabilities that the cost in each scenario is the lowest. Source: compiled by the authors.

Figure 13 describes the frequency distribution of the total management costs when using standard containers only (S0) and introducing $20 \%$ foldable containers (S4) in the 1000 scenarios, with $30 \%$ and $50 \%$ cargo shipping demand growth rates for random and biased demand patterns, respectively. The first finding is that, if fluctuations in cargo shipping demand are biased, empty container management costs are more widely distributed and have a higher probability of incurring higher costs than those in random demand fluctuations. The second is that the greater the growth in cargo shipping demand, the wider the distribution of empty container management costs. In other words, as cargo shipping demand increases, it becomes more difficult to control costs. The third is that, if cargo shipping demand increases by $50 \%$, the average, median, and mode of the distribution of total management costs are lower after introducing foldable containers, which implies that the introduction of foldable containers has a significant effect on cost reduction. The final, but most important, finding is that the frequency distribution of management costs in different time series of cargo shipping demand becomes much more concentrated by introducing foldable containers. This is because the introduction of foldable containers effectively mitigates the fluctuations in the number of empty containers that cannot be repositioned, owing to the fluctuations in cargo shipping demand. The fluctuation in storage costs and leasing fees of empty containers is reduced, which would influence the dispersion of management costs. This implies that the introduction of foldable containers also enables costs to be more stable and predictable, as well as to preserve the long-term sustainability of the shipping industry; therefore, it is more effective if the cargo shipping demand increases. 
Cases that use only standard containers
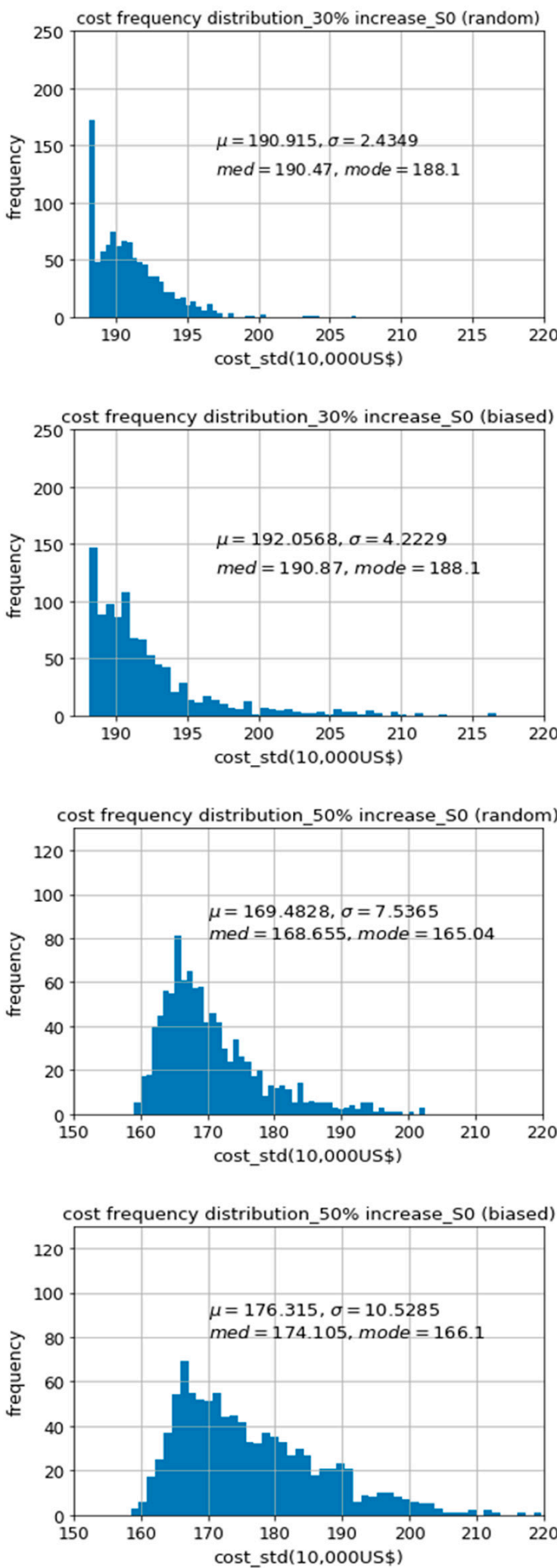

Cases that introduce foldable containers
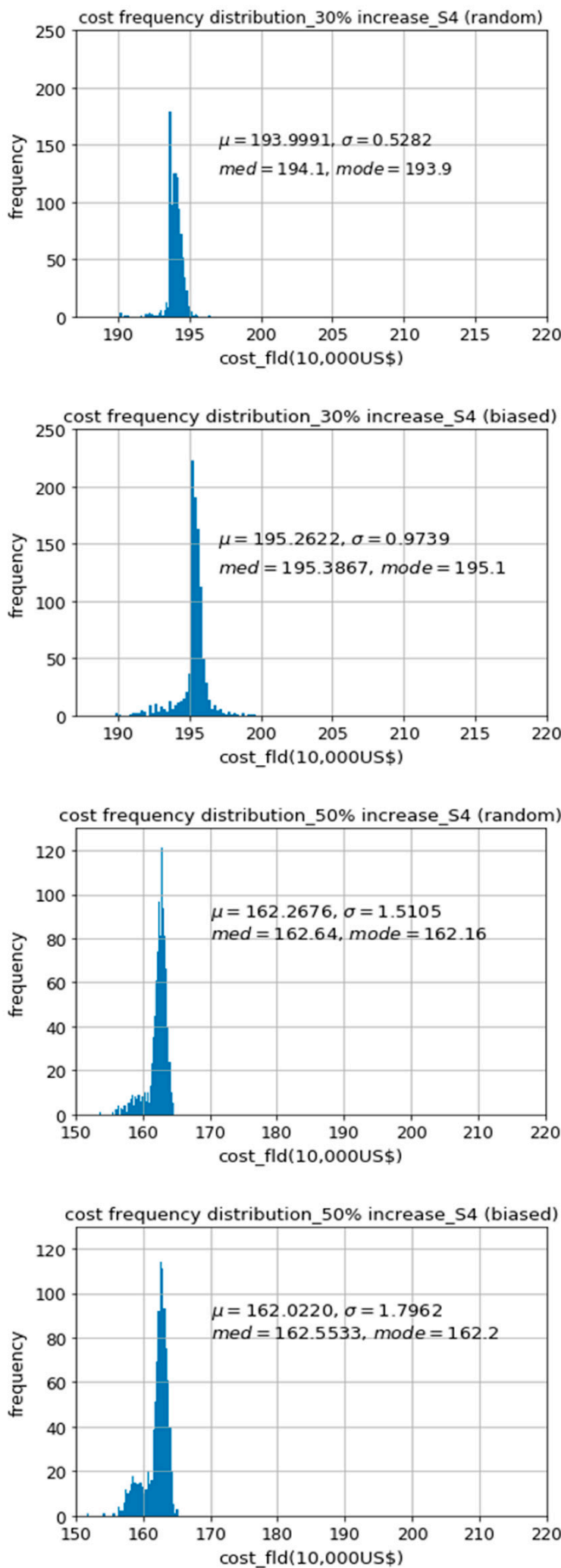

Figure 13. Frequency distribution of the total management costs of empty container repositioning for different scenarios ( $\mu=$ mean value, $\sigma=$ mean deviation, med $=$ median). Source: compiled by the authors. 


\section{Conclusions}

In recent years, rapid economic growth and globalization have increased the trade imbalance between Asia and the Pacific region, which has led to a serious problem of repositioning empty containers. One of the measures to alleviate this problem is the introduction of foldable containers, which have not yet been put to practical use. Therefore, to analyze whether foldable containers can be advantageous in empty container repositioning from an economic perspective, we compared the management costs of empty container repositioning when using only standard containers and introducing foldable containers. Specifically, we formulated the problem of empty container repositioning between East Asia and Oceania, based on the flow of full containers, and then we expressed the total management costs of container repositioning considering the introduction of foldable containers by using a mathematical model. We showed under what circumstances and to what extent foldable containers can contribute to the reduction of container management costs through scenario analyses, including static analysis and consecutive analysis with changeable cargo shipping demand. Furthermore, the cost reduction effect of adding another containership was considered if the future cargo shipping demand will increase substantially.

Based on the results of scenario analyses and simulations conducted, the following conclusions can be drawn. Firstly, with the introduction of foldable containers, the total management costs of container repositioning can be reduced depending on the growth rate of container cargo shipping demand. However, introducing too many foldable containers may increase the total management cost of container repositioning, because the related costs of foldable containers are relatively high. Therefore, the proportion of foldable containers is an important issue, and the related costs of foldable containers play a key role in the use of them. Secondly, if the container cargo shipping demand is extremely high, the surplus empty containers can be repositioned by an additional containership, which is more effective in reducing container management costs than introducing foldable containers. Thirdly, if fluctuations in cargo shipping demand are biased, empty container management costs are more widely distributed and have a higher probability of incurring higher costs than those in random demand fluctuations. However, with the introduction of foldable containers, it is more likely that the effect on cost reduction in the case of biased demand is greater than when the demand fluctuation is random. Finally, the distribution of empty container management costs would become much more concentrated after introducing foldable containers. This implies that the introduction of foldable containers not only effectively reduces the management costs of empty containers, but also makes costs more stable and predictable. In general, the results of this research provide useful managerial insights to the shipping company that the introduction rate of foldable containers significantly affects the cost reduction effect, and the shipping company should introduce an appropriate rate of foldable containers considering the cargo shipping demand and demand fluctuation pattern, which would promote the more efficient use of containers, and ensure the profits of the shipping company and the sustainability of the shipping industry. On the other hand, introducing foldable containers is not the only possible solution to the accumulation of empty containers; the management costs of empty container repositioning may become cheaper by introducing another containership to increase service frequency, in the case that future cargo shipping demand is expected to significantly increase. Therefore, the results of this study can support a shipping company's decision on whether to introduce a foldable container or an additional containership, and what proportion of foldable containers to introduce, considering cargo shipping demand.

Although Moon et al. [9] pointed out that foldable containers were not widely used because of higher production and folding/unfolding costs, the 3-in- 1 foldable containers with more advanced designs as adopted in this study could save the folding/unfolding costs, making them more advantageous. Moreover, similarly with this study, Lee and Moon [19] validated the advantage of using foldable containers in several consecutive demand scenarios; however, the effect on the cost-saving of introducing foldable containers was not significantly different between demand scenarios. In contrast, this study showed 
that introducing foldable containers has a greater effect on cost reduction in the case of biased demand rather than random demand. Meanwhile, they found an advantage in foldable containers even when the cargo shipping demand was relatively low, because there was not enough space on the containership to reposition empty containers in their case if compared to our simulation that focused on the PICs.

In summary, this study provided evidence for the economic feasibility of foldable containers for empty container repositioning. However, when an additional containership was introduced, we did not consider the changes in shipping demand for full containers caused by the doubling of service frequency. This is an important issue that should be addressed in future research. Moreover, regarding the fluctuation of cargo shipping demand, for simplicity, uniform distribution was considered when generating cargo shipping demand in this study. A more stochastic approach with various distributions will be discussed in future research. Furthermore, we focused only on one liner shipping service in the Pacific region. It would be interesting to extend the scope of this type of simulation and analysis to the global shipping network. In future research, we will analyze the empty container flow and make an efficient empty container repositioning plan considering multiple liner shipping services, based on the GMCSNS model [6,31]. By doing so, we could compare and analyze the cost reduction of empty container repositioning after introducing foldable containers, when considering multiple services.

Author Contributions: Conceptualization, R.S. and Y.H.; methodology, Z.L. and R.S.; software, Z.L.; validation, Z.L. and R.S.; formal analysis, Z.L.; investigation, Z.L., R.S. and Y.H.; resources, R.S. and Y.H.; data curation, Z.L.; writing-original draft preparation, Z.L.; writing-review and editing, R.S.; visualization, Z.L.; supervision, R.S.; project administration, R.S.; funding acquisition, Y.H. All authors have read and agreed to the published version of the manuscript.

Funding: This research received no external funding.

Institutional Review Board Statement: Not applicable.

Informed Consent Statement: Not applicable.

Data Availability Statement: Restrictions apply to the availability of these data. All data used in this paper were processed by the authors based on the data obtained from the third parties that the authors listed in the references as well as the authors' past studies. Therefore, they are available from the authors with the permission of these third parties.

Conflicts of Interest: The authors declare no conflict of interest.

\section{References}

1. Stopford, M. Maritime Economics; Routledge: London, UK, 2009.

2. Boxtics Inc. Available online: https:/ / boxtics.co.jp/ (accessed on 1 February 2021).

3. Shintani, K.; Konings, R.; Imai, A. The impact of foldable containers on container fleet management costs in hinterland transport. Transp. Res. Part E 2010, 46, 750-763. [CrossRef]

4. Yin, J.; Shi, J. Seasonality patterns in the container shipping freight rate market. Marit. Pol. Manag. 2018, 45, 159-173. [CrossRef]

5. Asian Development Bank. Trade and Maritime Transport Trends in the Pacific; Asian Development Bank: Manila, Philippines, 2020.

6. Riku, T.; Shibasaki, R.; Kato, H. Pacific Islands: Small and dispersed 'sea-locked' islands, In Global Logistics Network Modelling and Policy: Quantification and Analysis for International Freight; Shibasaki, R., Kato, H., Ducruet, C., Eds.; Elsevier: Amsterdam, The Netherlands, 2020; Chapter 14, pp. 277-299. [CrossRef]

7. Konings, R. Foldable containers to reduce the costs of empty transport? A cost-benefit analysis from a chain and multi-actor perspective. Marit. Econ. Logist. 2005, 7, 223-249. [CrossRef]

8. Shintani, K.; Konings, R.; Imai, A. The Effect of Foldable Containers on the Costs of Container Fleet Management in Liner Shipping Networks. Marit. Econ. Logist. 2012, 14, 455-479. [CrossRef]

9. Moon, I.K.; Do Ngoc, A.D.; Konings, R. Foldable and Standard Containers in Empty Container Repositioning. Transp. Res. Part E 2013, 49, 107-124. [CrossRef]

10. Myung, Y.S.; Moon, I.K. A Network Flow Model for the Optimal Allocation of Both Foldable and Standard Containers. Oper. Res. Lett. 2014, 42, 484-488. [CrossRef]

11. Bandara, Y.M.; Garaniya, V.; Chin, C.; Leong, Z.H. Improving logistics management using foldable/collapsible containers: A case study. Asian J. Shipp. Logist. 2015, 31, 161-185. [CrossRef] 
12. Moon, I.K.; Hong, H.J. Repositioning of Empty Containers Using both Standard and Foldable Containers. Marit. Econ. Logist. 2016, 18, 61-77. [CrossRef]

13. Wang, K.; Wang, S.; Zhen, L.; Qu, X. Ship type decision considering empty container repositioning and foldable containers. Transp. Res. Part E 2017, 108, 97-121. [CrossRef]

14. Zhang, S.; Ruan, X.; Xia, Y.; Feng, X. Foldable container in empty container repositioning in intermodal transportation network of Belt and Road Initiative: Strengths and limitations. Marit. Econ. Logist. 2018, 45, 351-369. [CrossRef]

15. Goh, S.H. The impact of foldable ocean containers on back haul shippers and carbon emissions. Transp. Res. Part D 2019, 67, 514-527. [CrossRef]

16. Zhang, R.; Huang, C.; Feng, X. Empty container repositioning with foldable containers in a river transport network considering the limitation of bridge heights. Transp. Res. Part A 2020, 133, 197-213. [CrossRef]

17. Lam, J.S.L.; Gu, Y. Port hinterland intermodal container flow optimization with green concerns: A literature review and research agenda. Int. J. Shipp. Transp. Logist. 2013, 5, 257-281. [CrossRef]

18. Hjortnaes, T.; Wiegmans, B.; Negenborn, R.R.; Zuidwijk, R.A.; Klijnhout, R. Minimizing cost of empty container repositioning in port hinterlands, while taking repair operations into account. J. Transport Geogr. 2017, 58, 209-219. [CrossRef]

19. Lee, S.; Moon, I. Robust empty container repositioning considering foldable containers. Eur. J. Oper. Res. 2020, 280, 909-925. [CrossRef]

20. Kuzmicz, K.A.; Pesch, E. Approaches to empty container repositioning problems in the context of Eurasian intermodal transportation. Omega 2019, 85, 194-213. [CrossRef]

21. Lam, S.-W.; Lee, L.-H.; Tang, L.-C. An approximate dynamic programming approach for the empty container allocation problem. Transp. Res. Part C 2007, 15, 265-277. [CrossRef]

22. Song, D.P.; Zhang, Q. A fluid flow model for empty container repositioning policy with a single port and stochastic demand SIAM J. Control Optim. 2010, 48, 3623-3642. [CrossRef]

23. Song, D.P.; Dong, J.X. Effectiveness of an empty container repositioning policy with flexible destination ports. Transp. Policy 2011, 18, 92-101. [CrossRef]

24. Zhang, B.; Ng, C.T.; Cheng, T.C.E. Multi-period empty container repositioning with stochastic demand and lost sales. J. Oper. Res. Soc. 2014, 65, 302-319. [CrossRef]

25. Dong, J.-X.; Song, D.-P. Container fleet sizing and empty repositioning in liner shipping systems. Transp. Res. Part E 2009, 45, 860-877. [CrossRef]

26. Song, D.-P.; Dong, J.-X. Empty container repositioning. In Handbook of Ocean Container Transport Logistics; Lee, C.Y., Meng, Q., Eds.; Springer: Berlin/Heidelberg, Germany, 2015; pp. 163-208.

27. Song, D.-P.; Carter, J. Empty container repositioning in liner shipping. Marit. Pol. Manag. 2009, 36, 291-307. [CrossRef]

28. Epstein, R.; Neely, A.; Valenzuela, F.; Hurtado, S.; Gonzalez, G.; Beiza, A.; Naveas, M.; Infante, F.; Alrcon, F.; Angulo, G.; et al. A strategic empty container logistics optimization in a major shipping company. Interfaces 2012, 42, 5-16. [CrossRef]

29. De, A.; Choudhary, A.; Turkay, M.; Tiwari, M.K. Bunkering policies for a fuel bunker management problem for liner shipping networks. Eur. J. Oper. Res. 2021, 289, 927-939. [CrossRef]

30. De, A.; Wang, J.; Tiwari, M.K. Fuel bunker management strategies within sustainable container shipping operation considering disruption and recovery policies. IEEE Trans. Eng. Manag. 2019. [CrossRef]

31. Shibasaki, R. Global maritime container shipping model. In Global Logistics Network Modelling and Policy: Quantification and Analysis for International Freight; Shibasaki, R., Kato, H., Ducruet, C., Eds.; Elsevier: Amsterdam, The Netherlands, 2020; Chapter 6, pp. 105-119. [CrossRef]

32. Shibasaki, R.; Kawasaki, T. A transhipment hub in South Asia and its competition: Application of network equilibrium assignment model for global maritime container shipping. Asian Transport Stud. 2019, 5, 546-569. [CrossRef]

33. Shintani, K.; Imai, A.; Nishimura, E.; Papadimitriou, S. The container shipping network design problem with empty container repositioning. Transp. Res. Part E 2017, 43, 39-59. [CrossRef] 